$$
N>0.29976
$$

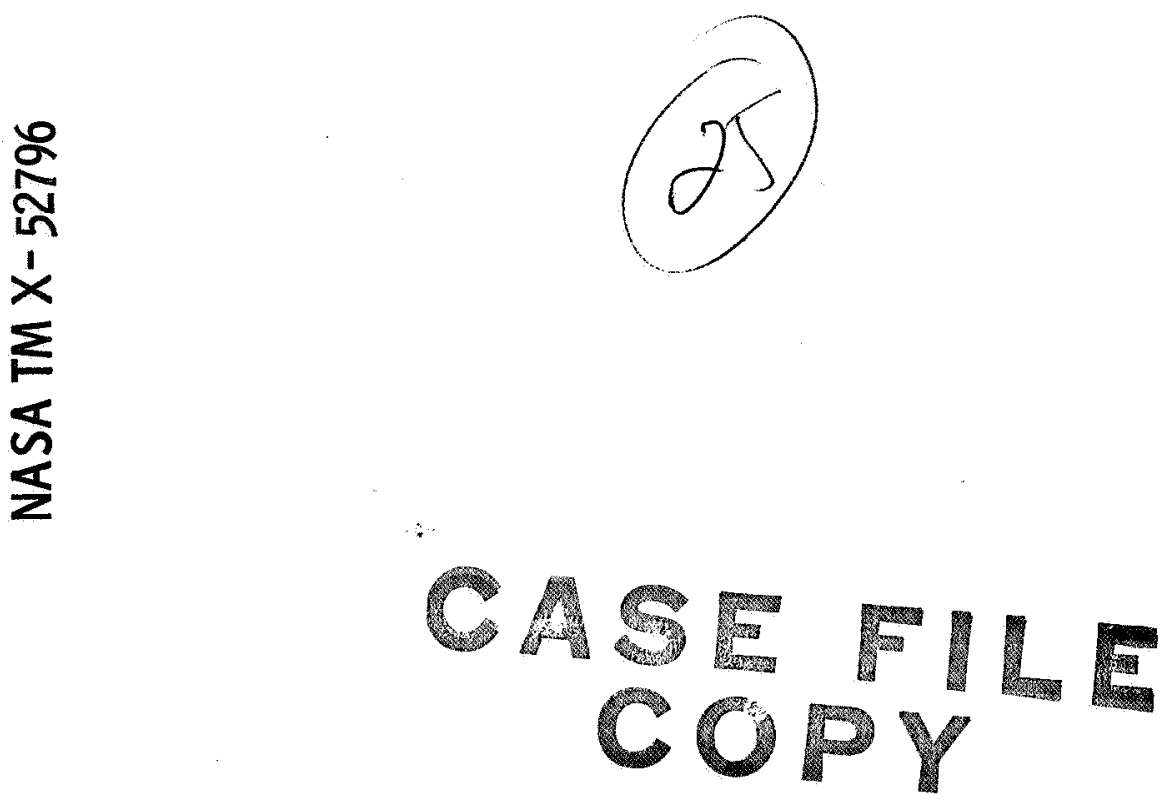

FLOXIMETHANE PUMP-FED ENGINE TECHNOLOGY REVIEW

by John W. Gregory

Lewis Research Center

Cleveland, Ohio

TECHNICAL PAPER proposed for presentation at

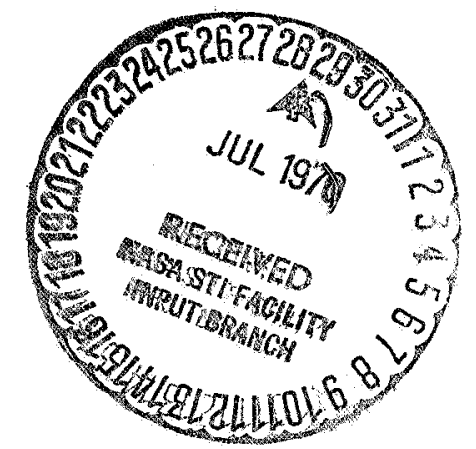
Sixth Propulsion Joint Specialist Conference sponsored by the American Institute of Aeronautics and Astronautics San Diego, California, June 15-19, 1970 
FLOX/METHANE PUMP-FED ENGINE TECHNOLOGY REVIEW

by John W. Gregory

Lewis Research Center

Cleveland, Ohio

TECHNICAL PAPER proposed for presentation at Sixth Propulsion Joint Specialist Conference sponsored by the American Institute of Aeronautics and Astronautics San Diego, California, June 15-19, 1970 


\title{
FLOX/METHANE PUMP-FED ENGINE TECHNOLOGY REVIEW
}

\author{
John W. Gregory
}

\author{
Lewis Research Center \\ National Aeronautics and Space Administration \\ Cleveland, Ohio
}

\section{Abstract}

A comprehensive program, sponsored by NASALeRC during the past several years, has provided the technology groundwork for application of FLOX/methane propellants to pump-fed rocket engines. Injectors have been developed utilizing liquid oxidizer/gaseous fuel. Regeneratively cooled thrust chambers have been designed, fabricated, and tested. Altitude performance data has been obtained with high expansion ratio nozzles. Optimum turbopump drive cycles and turbomachinery arrangements have been selected. Turbomachinery and valve critical design criteria have been obtained through experimental work on bearings, seals, and shutoff valves operating in fluorine. This paper summarizes the results of the above programs.

\section{Introduction}

For the past several years, NASA has been sponsoring, through the Office of Advanced Research and Technology, an extensive program to advance the technology of space storable propellants. The definition of this class of propellants, the justification for investigating them, and the delineation of the types of missions for which they are applicable have been discussed at length by previous authors. $(1,2,3)$ Summarizing these briefly, space storable propellants are intended for use in deep space missions where a sizeable velocity change is required for a spacecraft after a long space coast of perhaps 1 to 4 years. The principal attributes required to satisfy this requirement are that the propellants can be easily stored in space for long periods of time and have high performance. Other desirable attributes of these propellants include high bulk density, hypergolic ignition, overlapping or contiguous liquid ranges of the fuel and oxidizer, and the ability of one of the propellants to serve as a coolant for the thrust chamber. Early studies of the various competing propellant combinations within this class, which includes $\mathrm{OF}_{2}-\mathrm{B}_{2} \mathrm{H}_{6}$ and FLOX/light hydrocarbon fuels, indicated that FLOX/ methane best satisfied all of the above requirements, and the Lewis Research Center program has recently concentrated efforts on this combination.

\section{Selection of Operating Conditions}

Recent mission studies $(3,4)$ have described a variety of planetary probe missions for which the space storable propellant combinations are well suited. For these missions, the optimum engine thrust levels were in the range from 2000 to $8000 \mathrm{lb}$. With this in mind, a thrust level of $5000 \mathrm{lb}$ was chosen for the Lewis' FLOX-methane program as being a representative value that is appropriate for real applications. This thrust level was also deemed to be a reasonable size at which to evaluate problems that are typical of engines of the above thrust range. The question of pump-fed versus pressure-fed engines was also considered and, in fact, the Lewis program has encompassed work applicable to both types of engines. The program initially was aimed principally at pressure-fed engines. Later, emphasis was shifted more to pump-fed engines when it became evident that pump-fed engines of this size range using these propellants were entirely feasible. Also, they provide smaller, lighter weight, higher performance engines. This decision was also based on the fact that methane is a good supercritical coolant for use in regenerative thrust chambers and has excellent characteristics as a turbine working fluid.

The advantages of regenerative cooling of rocket thrust chambers are well known throughout the industry. This cooling method involves no performance losses, as with film or transpiration cooling, is not short life limited, like ablation cooling, and provides a chamber with cool outer walls, as opposed to radiation cooling. The use of regenerative cooling for small engines (either pump-fed or pressure-fed), and particularly tho se using high energy propellants, has been limited due to the pressure drop required, the high heat flux levels encountered, and problems associated with boiling of the coolant for low chamber pressure engines where coolant pressures were below critical pressure.

Because of these potential limitations, the use of regenerative cooling for small, pump-fed regeneratively cooled FIOX/methane engines was studied in detail to determine the ranges of thrust and chamber pressure within which it was applicable. $(5,6,7,8)$ These studies considered the effects of wall temperature, wall material, mixture ratio, nozzle area ratio, and the percent of theoretically predicted heat flux which the chamber would actually encounter. This latter factor is influenced by the injector design and the amount of carbon deposition occurring on the hot side chamber walls. The studies also took into account the practical limitations associated with fabrication of a thrust chamber, such as the minimum size coolant channels that can be fabricated successfully and the variations in height and width of these channels along the length of the chamber.

The results of the analysis of regenerative cooling limits indicated that operation at chamber pressures up to 1000 psia was technically feasible. Selection of a high chamber pressure is desirable to provide a small engine envelope, particularly for an upper stage engine of this type where the use of a large expansion ratio nozzle is desired to obtain high delivered specific impulse. A chamber pressure of 500 psia was selected as a nominal design point value. Selection of this value alleviates potential heat transfer and chamber fabrica- 
tion problems that would accrue from use of a higher chamber pressure and provides room for engine thrust uprating.

Once the major engine characteristics had been selected, the Lewis FLOX/methane program was configured to provide the technology groundwork for the various appropriate engine components. In this paper, the results of the program in the areas of gas/liquid injectors, regenerative thrust chambers, turbopump drive cycle analysis, turbomachinery, and valves will be presented. The application of this technology to a space storable research engine and a FLOX/methane propulsion module will be discussed. Table 1 summarizes the nominal operating conditions for a pump-fed, FLOX/ methane engine about which the program has been focused.

\section{Injectors}

In designing injectors for FLOX/methane propellants, it is particularly important to obtain good mixing and uniform mass and mixture ratio distribution. These requirements are imposed because the optimum performance mixture ratio (5.75) is also the stoichiometric mixture ratio and because the performance versus mixture ratio curves peak sharply. For the engine characteristics listed in Table 1 , the methane fuel passes through the regenerative thrust chamber before entering the injector. Theoretical calculations predicted fuel temperatures of approximately $800^{\circ}$ to $1000^{\circ} \mathrm{F}$ at the outlet of the regenerative chamber, depending upon the magnitude of the heat reduction factor $Q_{m} / Q_{p}$. Injector designs were, therefore, based on gaseous fuel at this temperature level. The oxidizer would be a cryogenic liquid entering the injector. Test facilities were set up to perform injector tests with both water-cooled thrust chambers and regenerative thrust chambers. For the water-cooled chamber testing, heat exchangers were used to heat the methane fuel, prior to routing it to the injector, thereby simulating the regeneratively cooled case.

A variety of injector element types have been designed and tested including concentric tube, pentad (4 oxidizer on 1 fuel), and triplet designs. $(8,9,10,11)$ From these tests, the concentric tube injector has emerged as the most desirable from the standpoints of high performance, good durability, combustion stability, and provision of low chamber heat transfer rates. A typical FLOX/methane concentric tube injector design is shown in Fig. 1. $(9,12)$ In this particular design, the oxidizer spud plate was constructed of nickel because of its high thermal conductivity and good fluorine compatibility. Hydraulic swirler caps were used to impart a strong vortex flow in the oxidizer tubes, causing the oxidizer flow leaving the tube to form a hollow cone spray. This injector has been tested with a solid copper faceplate and porous Rigimesh face plates of two dif-: ferent porosities $(40-$ and $100-\mathrm{scfm})$. In this particular design, the fuel is directed inward to impinge with the oxidizer spray to promote rapid atomization and mixing. Concentricity of the fuel annulus with the oxidizer post is maintained oy the use of small spacers.
A variation of the concentric tube design, shown in Fig. 2, is the scarfed-element injector. (12) In this design, the two outer rows of elements have the oxidizer tubes protruding from the face and cut off at an angle (scarfed). This causes the oxidizer spray cone to be bent slightly inward away from the thrust chamber wall. Fig. 3 shows a comparison of the spray from scarfed and unscarfed elements illustrating how the spray is directed inward. The specific purpose of this design was to reduce the thrust chamber heat flux in the chamber region while maintaining high $C^{*}$ efficiency. In this design, a composite Rigimesh face plate, having high porosity in the outer ring $(100 \mathrm{scfm})$ and low porosity in the center core $(40 \mathrm{scfm})$, was used. The purpose of this design was to provide additional injector face cooling and a slightly lower mixture ratio in the outer periphery of the chamber. The fuel was injected parallel to the oxidizer tubes rather than impinging.

The performance of these particular injector designs is shown in Fig. 4, in which characteristic velocity (C*) efficiency is presented as a function of mixture ratio. This data was obtained with cylindrical cooled thrust chambers having a characteristic length $\left(L^{*}\right)$ of 52 in. and a contraction ratio of 4 . Data obtained with an $\mathrm{L}^{*}$ of $30 \mathrm{in}$. showed a drop in performance of 1.5 to 2.0 percent. Comparing the performance of the concentric tube injector with the $100 \mathrm{-scfm}$ face plate and the 40-scfm face plate shows a drop in performance of about 1 percent with the higher porosity Rigimesh. The scarfed-element injector provided comparable performance to the concentric tube injector with the 100 -scfm face plate. This $C^{*}$ data was corrected for propellant inlet temperatures and chamber heat transfer to nominal conditions for a regeneratively cooled engine using liquid propellants.

High $\mathrm{C}^{*}$ efficiencies (above 97 percent) have been obtained in other testing with both fixed thrust and throttling injectors of the concentric tube type, which are shown in Fig. 5. (13) Fig. 5(a) is a concentric tube fixed thrust design which utilized swirler caps for the oxidizer, slightly recessed stainless steel oxidizer tubes, and a solid copper face plate. Two throttling injector designs are also shown, a heat exchanger type (Fig. 5(b)) and a recessed post design (Fig. 5(c)). The heat exchanger type is designed to gasify the oxidizer by exchanging heat with the warm fuel. The oxidizer swirler and relatively long tube are designed for this purpose. When throttled, this injector is designed to provide higher oxidizer pressure drop than would result if the oxidizer remained as a liquid. The recessed post throttling injector is also designed to maintain high oxidizer pressure drop as flow is reduced. As flow is throttled, the hydraulic pressure drop due to the restrictor decreases rapidly (as the square of the flow), but the pressure drop due to combustion in the "cup" region increases because of increased mixing.

Testing of these injectors is still in progress and consequently, the results are not yet available. Preliminary indications are that recessing the oxidizer post an amount equal to the oxidizer tube diameter was 
not sufficient to provide stable combustion and high performance down to 50 psia chamber pressure. Chugging instability, which occurred at low chamber pressures was thought to be due to partial vaporization of the oxidizer. Additional testing is planned to further evaluate this injector.

The injector designs previously discussed represent the best designs from the standpoints of performance, durability, and ability to provide acceptable chamber heat transfer conditions. A variety of other injector types were also tested with less favo rable results in these areas. Through this injector test program, the aforementioned difficulty of obtaining high performance with these propellants became evident. Other injector oriented programs were, therefore, initiated with the objective of pursuing a more fundamental approach to injector design. $(14,15,16)$ In these programs, an effort has been made to obtain a full understanding of the factors that contribute to combustion performance losses. In these programs, cold flow tests have been made with simulated gas-liquid and liquid-liquid propellants to determine the effects of injector design variables on the propellant mass and mixture ratio distribution and droplet size distribution. Apparatus was set up initially for evaluation of liquid-liquid propellant injector elements in which the simulated propellant flows (water and trichlorethylene) were collected. Fig. 6 shows the spray collector grid and shutter arrangement used for the se tests. Evaluation of this data provided the mass and mixture ratio distribution of the various injector element types as functions of design and operating variables. Subsequently, the apparatus was modified for simulated gas-liquid cold flows wherein the simulants were sprayed into a pressurized enclo sure and the spray sampled with a moveable probe to determine the distribution of both the fuel and oxidizer. These tests are still in progress. and the results are not yet available.

The droplet size distribution for the same element types was obtained by the use of a hot wax flow test apparatus. In these tests, molten wax is used as the liquid propellant simulant. This is flowed through typical injector elements, the spray frozen and collected. and the resultant wax globules sieved to determine the size distribution. These results are correlated with analytical predictions and results of previous experimenters to verify the data. This work utilized identical apparatus and procedures as reported in Ref. 39 .

For a typical injector element type, such as the concentric tube injector, data may be obtained on the expected propellant mass and mixture ratio distribution and droplet size distribution from cold flow tests and hot wax flow tests, respectively. From this data, the performance of the injector may be analytically predicted considering that all of the combustion losses will be caused by either lack of propellant vaporization or maldistribution of the propellants. (15) Using these techniques, the concentric tube injector design, for example, may be optimized with respect to velocity ratios, recessing of the oxidizer post, or the swirler design prior to hot firing tests with reasonable assurance that the predicted performance will be realized.

\section{Thrust Chamber Cooling}

Typically, in the design of regeneratively cooled rocket thrust chambers, it is necessary to know the heat flux levels along the chamber length produced by a particular injector/chamber combination. This is particularly true for high performance engines where heat flux levels are high and thrust chamber designs, therefore, more critical. If the heat flux levels can be reduced, for example, by injector design changes, the chamber can generally be cooled more easily with less coolant pressure drop, larger coolant flow passages, lower coolant discharge temperatures, or lower wall temperatures. These factors contribute to a more durable and higher performing engine.

In conjunction with the injector evaluations discussed in the previous section, data was obtained on thrust chamber heat transfer by the use of water-cooled chambers. $(9,12,13)$ This data was obtained for use in the design of regeneratively cooled chambers and to determine the actual heat flux levels with carbon deposition on the chamber walls compared to tho se analytically predicted for clean walls. A typical water-cooled thrust chamber assembly is shown in Fig. 7. The watercooled chambers were designed for the operating conditions given in Table 1 . The coolant passages were arranged to provide data on axial and circumferential heat flux profiles. Data was obtained with these chambers at chamber pressures from 50 psia to 900 psia and for mixture ratios from 4.0 to 6.0 .

The overall heat transfer data obtained with the concentric tube injectors shown in Figs. 1 and 2 is presented in Fig. 8 as a function of mixture ratio. This data is for the complete thrust chamber including the nozzle with an expansion area ratio of 60:1. Consideration of the two upper curves indicates that the heat transfer was reduced markedly by the use of the more porous $100 \mathrm{scfm}$ face plate as compared to the $40 \mathrm{scfm}$ face plate. However, the performance data shown in Fig. 4 for these injectors shows that the $100 \mathrm{scfm}$ face plate injector was also lower in performance. The scarfed element injector provided a further reduction in heat transfer and equivalent performance to the concentric tube injector with the $100-\mathrm{scfm}$ face plate. These results show the value in the scarfed element injector design of directing the outer oxidizer sprays away from the chamber wall and of using the composite Rigimesh face plate with the more porous region near the wall. They also show the sizeable changes that can be made in chamber heat transfer by injector design tailoring without loss of $\mathrm{C}^{*}$ efficiency. The throat and nozzle heat flux for these three injectors was about the same but the combustion chamber heat flux was greatly different.

The heat flux profile data obtained with the concentric tube injector and the recessed post injector, shown in Fig. 5, are presented in Fig. 9. These curves show the axial heat flux profiles along the chamber and the effect of increasing chamber pressure from 60 psia to 875 psia. This data was obtained with a water-cooled chamber having a nożzle area ratio of 4:1. During these tests, the carbon deposition on the chamber walls 
was relatively light except in the region near the injector face where thicker, sooty deposits were formed.

In designing chambers for FLOX/methane, some difficulty has been experienced in the past in determining the effect of carbon deposition on heat transfer and separating this from injector effects. Experimentally measured overall heat transfer has been generally found to be less than that theoretically predicted $\left(Q_{m} / Q_{p}\right)$ and the reduction in measured heat transfer has been accredited to carbon deposition. However, recent data suggests that injector design effects are much more important than carbon deposition in influencing chamber heat transfer. This is not only true at design conditions, but also at off-design conditions, for example, for a throttling injector at low chamber pressures.

Also, for the case of throttling, attention must be given to the coolant temperature leaving the chamber, which tends to rise as the engine is throttled. Previous studies of cooling limits $(6,7)$ generally concluded that the limiting operating temperature for methane was about $1400^{\circ} \mathrm{F}$. Operation at temperatures in excess of this could lead to excessive thermal decomposition in the coolant channels. This would result in carbon formation and possible plugging or blockage of the channels. This problem may be avoided by shifting to lower mixture ratios as the engine is throttled.

\section{Thrust Chamber Fabrication}

The experimental heat transfer results enumerated above along with the regenerative cooling studies pointed out the necessity for development of new methods of fabricating regenerative thrust chambers. This requirement is brought about by the need for extremely small coolant passages at the throat station, the need for close control of the dimensional tolerances of these passages, and the need for flexibility in passage width and height along the chamber length.

For the past several years, the Lewis advanced technology program has encompassed work on advanced regenerative thrust chamber fabrication methods. The goals of these programs have been to apply new fabrication techniques that provide the advantages of low cost, greater flexibility, and shorter build-up time for the chambers. The resulting chamber designs make use of coolant channels rather than tubes, are capable of handling high heat flux levels, and make use of high thermal conductivity materials, such as nickel.

Previous methods of fabrication, such as the use of brazed assemblies of drawn and tapered stainless steel tubes, were inadequate. Fig. 10 presents a comparison of the regenerative cooling limits for tube bundle chambers compared to an advanced coolant channel ${ }^{(6)}$ chamber for a range of thrust levels. The cooling limit for the advanced chamber was established by the coolant pressure drop being not greater than one-half of chamber pressure. For the tubular chamber, the cooling limit was based upon stress and wall temperature considerations for the smallest size tube ID considered reasonable (0.040 in.). The advantage of the more advanced fab- rication method is apparent.

A variety of new fabrication techniques have been evaluated, including electroforming, chemical milling, electrodischarge machining, electron beam welding, vacuum deposition, and diffusion bonding. A large number of contracts have been placed in this general area of fabrication methods, which cannot be covered in this paper. Two specific chamber fabrication procedures will be discussed which were directly a part of the FLOX/methane program.

Under contract NAS3-11190, a regenerative thrust chamber was designed for the operating conditions listed in Table 1 based on heat transfer data obtained from the water-cooled thrust chamber tests. This chamber was built using the thermal skin approach, which has been previously described in the literature. $(5,6,9,11,12,17)$ In this fabrication method, the chamber was built up as follows:

1. Nickel plates for the inner walls and Inconel 600 plates for the outer walls were photoengraved to obtain the coolant passages. A typical engraved nickel plate is shown in Fig. 11.

2. The nickel and Inconel plates are bonded together by brazing or diffusion bonding while still flat.

3. The nickel/Tnconel sandwich is then formed to the proper shape and contour and trimmed to the proper dimensions. Fig. 12 shows one such chamber segment or "stave" after these operations have been completed.

4. Six of these staves are then assembled together on a fixture and welded together. The coolant manifolds, flanges, and a strengthening jacket around the chamber region are then welded in place to form a complete thrust chamber.

This chamber fabrication technique has been improved through a series of evaluative regenerative cooling tests and chamber redesigns. The principal problems encountered with this technique are that the welding operations to attach the staves together tend to cause overheating of the braze joint, which causes the braze to soften and flow, creating unbonded locations and partial blockage of the outermost channels. To correct this problem, it was decided to use electron beam (EB)-welding rather than hand welding to attach the staves together in the second chamber built. Use of this process allowed the weld to be completed in one pass from the outside, produced a very narrow weld bead, and did not adversely affect the braze joint. Other design improvements included enlarging the outer coolant channels to 25 percent greater flow areas than the other channels to provide overcooling of this area. Also, the nickel and Inconel plates were joined by diffusion bonding, rather than brazing, to eliminate the problems of braze migration, after preliminary tests had been completed which assured that a satisfactory bond could be obtained. The chambers being fabricated according to the latest design have not yet been tested and, therefore, the validity of these improvements has not been proven.

The second type of regenerative chamber to be discussed was an electroformed nickel chamber, which was built under contract NAS3-11191. $(7,13)$ This 
chamber was also designed for the conditions given in Table 1. The chamber was built in two parts: the combustion chamber and throat section, shown in Fig. 13, and the high expansion ratio nozzle portion, shown in Fig. 14. The chamber and nozzle were formed by electrodeposition of nickel onto mandrels in electrolytic baths. The inner wall was deposited to a thickness great enough to include the hot wall thickness and the depth of the coolant channel. The piece was then removed from the bath and machined to the correct contour. The coolant channels were machined in place using a milling machine. The coolant channels were then filled with wax and the outer wall electroformed in place. The wax was then removed from the channels. Welding on of the flanges and manifolds completed fabrication of the chamber.

This thrust chamber was tested several times at chamber pressures from 200 to 500 psia and mixture ratios from 4.0 to 6.0 before any structural faults were observed. Following a test in which a high mixture ratio cutoff occurred, a blister was observed in the inner wall in the convergent portion of the nozzle. Inspection of this area revealed that separation of the metal had occurred on the outer edge of the ribs. This was probably due to poor bonding of the outer wall to the ribs in this area after the wax had been placed in the coolant channels and electroforming resumed. However, the chamber had passed a proof pressure test and the high temperature cutoff evidently exceeded design limits.

Although some problems have been encountered in these advanced chamber fabrication programs, much has been learned about the processes involved and how to apply them satisfactorily. It is now felt that either of the processes described above could be developed into a method of producing chambers quickly and cheaply in large numbers.

\section{Altitude Performance}

Tests have been performed at simulated altitude exhaust conditions with both water-cooled and regeneratively-cooled thrust chambers. $(9,12,13)$ From these tests, data has been obtained on the delivered specific impulse and nozzle thrust coefficient efficiency attainable for the 60:1 expansion ratio nozzle. Vacuum specific impulse data is presented in Fig. 15(a) for the same injectors for which the $C^{*}$ efficiency data was given in Fig. 4. The data presented were calculated from measured values of thrust and flow rates with no corrections applied. The highest specific impulse, which was obtained with the unscarfed concentric tube injector with the 40 -sefm face plate, was about $396 \mathrm{sec}$ at a mixture ratio of 5.0 to 5.5. The unscarfed concentric tube injector was tested with both the 40-scfm and 100-scfm Rigimesh face plates and the higher performance was achieved with the lower porosity face plate. This data was obtained at a chamber pressure of 500 psia using a chamber $L^{*}$ of 52 in.

The calculated nozzle thrust coefficient efficiencies are shown in Fig. 15(b). The same corrections were applied to the nozzle performance data as were used for the $C^{*}$ efficiency data, as previously discussed. The thrust chamber and nozzle contour for which this data applies is shown in Fig. 16. ${ }^{(9)}$ The nozzle has a radius of curvature at the throat equal to the throat radius. The supersonic nozzle contour was determined using a method of characteristics solution. The contour corresponds to that for a minimum surface area design; it is an ideal expansion ratio of $110: 1$ truncated to $60: 1$. A nozzle stream thrust coefficient of 97.3 percent was computed for the-contour considering divergence, friction, and transonic flow nonuniformity. The thrust coefficient efficiency data for the three injectors falls in a band from about 95.5 to 96.5 percent at a mixture ratio of 5.25. This would indicate potential nozzle kinetic losses of about 0.8 to 1.8 percent at this mixture ratio.

For a number of years, Lewis has sponsored research in the area of nozzle nonequilibrium performance. Initially, this work was devoted to hydrogenfluorine propellants. Both analytical and experimental work was accomplished, computer programs were written, and correlations made between the analytical predictions and the experimental results forthcoming from several sources. $(19,20,21,22)$ More recently, the analytical techniques and some of the chemical reaction rates and mechanisms used in the above programs have been applied to the space storable propellant combinations. $(23,24)$

Experimental work has also been done with the space storable propellants, $\mathrm{OF}_{2}-\mathrm{B}_{2} \mathrm{H}_{6}, \mathrm{FLOX}-\mathrm{B}_{2} \mathrm{H}_{6}$, $\mathrm{OF}_{2}-\mathrm{CH}_{4}$, and FLOX $-\mathrm{CH}_{4}$ to determine the achievable delivered specific impulse and provide a direct comparison of the performance of these propellants. (26) This work was done at a chamber pressure of 100 psia to amplify kinetic effects using both conical and contoured nozzles with area ratios of $60: 1$. These experimental results have been compared to the performance that would be predicted analytically taking into account divergence, friction, transonic, heat transfer, and kinetic losses. A typical result of such comparisons is shown in Fig. $17^{(24)}$ which is for FLOX-methane propellants at a chamber pressure of 100 psia and a $15^{\circ}$ conical nozzle having an area ratio of 60 . In this particular example, the experimental results are within about \pm 1 percent of the theoretical prediction. In general, the theoretical method provided predictions that correlated with the bulk of the experimental data within \pm 2 percent.

- Based on these results, a NASA Kinetic Performance Handbook ${ }^{(25)}$ will soon be published which will present computed kinetic data for calculation of nozzle performance for several propellant combinations. The procedures and reaction rate constants will be consistent with tho se recommended by the ICRPG Performance Standardization Working Group. The NASA Kinetic Performance Handbook, ${ }^{(25)}$ when published, will provide a useful tool for calculation of kinetic performance at chamber pressures up to 1000 psia. 
Ref. 23 provides theoretical kinetic performance predictions for FLOX-methane at 300 psia chamber pressure and a nozzle area ratio of 40 . For these conditions, this reference predicts about 1.5 percent performance loss due to nozzle nonequilibrium performance at an $\mathrm{O} / \mathrm{F}$ of 5.25. This is consistent with the data presented in Fig. 15, since the kinetic loss would be somewhat smaller at higher chamber pressure.

\section{Engine Cycle Studies}

A major consideration in the design of a pump-fed rocket engine is selection of the optimum turbopump drive cycle. Two parallel studies were initiated in 1968 for the purpo se of evaluating the various turbopump drive cycles and turbomachinery arrangements applicable to a small FLOX/methane engine, selecting the optimum cycle, and completing a preliminary design of the engine. $(17,18)$

Initially, in these studies, heat transfer calculations were performed for regeneratively cooled thrust chambers for a range of operating conditions. From these calculations, the methane coolant pressure drop and temperature rise were predicted based on the use of advanced thrust chamber designs and fabrication techniques of the types previously discussed. Based on this information, the various cycles were studied for the two design points listed in Table 2. A mixture ratio of 5.25 was used for the design points rather than the optimum theoretical $\mathrm{O} / \mathrm{F}$ of 5.75 because experimental performance peaks at the lower $\mathrm{O} / \mathrm{F}$ and its use eases the regenerative cooling design.

The engine turbopump drive cycles studied, shown in Fig. 18, included the expander, auxiliary heat exchanger, gas generator, staged combustion, and chamber tapoff cycles. In these studies, calculations were made of the performance losses associated with the cycle. Such losses occur in the so-called "open" cycles where the turbine drive gases are dumped overboard through an auxiliary nozzle or are routed to the main nozzle at a relatively high area ratio. The engine weight was calculated for each cycle being considered. The characteristics of the pumps and turbines were evaluated for each cycle and for four different turbomachinery arrangements, as follows: single turbine, gear drive; single turbine, direct drive; parallel turbines, and series turbines. The pump discharge pressures, pump and turbine efficiencies, and rotating speeds were calculated for each case.

Potential engine development problems were evaluated for each cycle. One of the more serious problems that became evident was the use of combustion products containing $\mathrm{HF}$ and free carbon to drive the turbine, such as would be the case for the gas generator, chamber tapoff, and staged combustion cycles. Experience with other engines employing carbon containing turbine drive gas has taught that partial plugging of the turbine inlet stator can result. For a small engine of this type, serious degradation of turbine power would quickly occur if carbon plated out on the turbine inlet stators, since the stator height is of the order of 0.20 to $0.25 \mathrm{in}$.
Consideration of this problem narrowed the study to a more in-depth evaluation of the expander and auxiliary heat exchanger cycles, both of which employ heated methane gas to drive the turbine.

Cycle balances were made for these cycles for the nominal operating conditions and the cycle operation at off-design point conditions was also evaluated. Table 3 presents some of the principal characteristics of an expander cycle engine designed for 500 psia chamber pressure, an $\mathrm{O} / \mathrm{F}$ of 5.25 , and a heat flux ratio of 0.9 . The turbine bypass flow of 25 percent indicates that the expander cycle power margin is 25 percent. These calculations are for a single turbine, gear drive turbomachinery arrangement where the turbine drives the fuel pump directly at $50,500 \mathrm{rpm}$ and is geared down $2: 1$ to drive the oxidizer pump. It is evident from Table 3 that the cycle power margin is insensitive to changes in the heat input to the coolant over the range that might result from injector design changes. Variations in mixture ratio also would result in relatively small changes in pump output conditions and power margin. The engine could be uprated to a chamber pressure of 800 psia, which would result in an increase in thrust to about $8000 \mathrm{lb}$, by increasing the turbine speed to $68,000 \mathrm{rpm}$. The power margin would be decreased to 10 percent. The last column of Table 3 gives the conditions for 10:1 throttled operation.

The auxiliary heat exchanger cycle was also evaluated for off-design point operation and it was learned that an additional flow control valve would be needed for throttling to bypass flow around the turbine. This is required because the flow required to cool the nozzle and the turbine flow required to supply power to the pumps do not remain matched as the engine is throttled. Other drawbacks of the auxiliary heat exchanger are that it provides about 1 percent lower delivered specific impulse than the expander cycle and, for the same chamber mixture ratio, the auxiliary heat exchanger cycle results in a lower engine mixture ratio because the turbine drive fuel does not pass through the combustion chamber. At the conclusion of the studies, the expander cycle and the 500 psia chamber pressure design point were chosen for the engine preliminary designs.

In the two parallel studies made of the turbopump drive cycles, different approaches were taken for the turbomachinery arrangement for the expander cycle engine. In one case, separate parallel turbines were selected to drive the fuel and oxidizer pumps, and in the second case, a single turbine with gear drive was selected. The parallel turbine approach is depicted in Fig. 19. In this arrangement, a bypass valve is used to route methane flow around the turbines, thereby providing thrust control. A throttling control valve in the oxidizer turbine feed line provides control of mixture ratio. This arrangement provides greater flexibility for turbopump control during startup and shutdown and for off-design point operation. However, it has the disadvantage that for low NPSH operation, the oxidizer turbopump speed must be relatively low, which compromises the turbine efficiency. 
In the single turbine, gear drive arrangement, thrust control is obtained by the use of a bypass valve to route flow around the turbine and $\mathrm{O} / \mathrm{F}$ control is obtained by the use of a throttling control valve in the oxidizer line between the pump and the injector. The advantages of the single turbine, gear drive arrangement are that it allows optimization of the oxidizer pump speed independent of the turbine speed required, and provides a light weight, compact turbomachinery package. Its advantages are the loss of flexibility during offdesign operation imposed by mechanical linking of the pumps and the added requirement for development of a reliable gear train.

\section{Turbomachinery}

One of the principal prerequisites to development of a small, pump-fed FLOX/methane engine was known to be the development of technology for the turbomachinery. Some of the unusual characteristics of the turbomachines for this application are their small size, making high efficiency difficult to realize, and the requirement for an oxidizer pump for 82.6 percent FLOX. For the latter requirement, a great deal of experience has been gained from the program for application of hydrogen-fluorine propellants to the RL10 engine. $(27,28)$ Under these contracts and in tests conducted in-house at Lewis, $(29,30)$ an extensive investigation was made of seal materials for fluorine pumps. The fluorine pump shaft seal package design is shown in Fig. 20, which is a crosssectional view of the RL10A-3-3 oxidizer pump, as modified for fluorine service. The seal package design that was devised to separate the liquid fluorine at the impeller back faoe from the gear box (which contains fuel) consists of four seals with a vent between the No. $1\left(\mathrm{LF}_{2}\right)$ seal and No. 2 seal, a helium dam between the No. 2 and No. 3 (intermediate) seals, and a vent between the No. 3 and No. 4 (gearbox) seals. The carbon seals that were normally used were unsuitable for use in the first 3 seal locations because the carbon would react with fluorine, and substitute materials were necessary. A total of five seal material combinations were evaluated for the No. 1 seal ( $\mathrm{LF}_{2}$ seal) and five combinations for the intermediate seals. Seal rig and liquid fluorine pump tests were conducted at various speeds and loads to evaluate the compatibility, wear rates, and resistance to thermal cycling. of the various materials. The best materials for the liquid fluorine seal were a titanium carbide-nickel cermet (Kentanium K162B) seal plate and nose piece. For the intermediate seals, the best materials were solid aluminum oxide rubbing against a K162B seal plate. These materials were successfully employed in the fluorine pump for all of the hydrogen-fluorine RL10 engine firings under contract NAS3-7991 without incident. They were also designated for the FLOX pump preliminary designs for the 5000-1b thrust FLOX-methane engine in the two previously mentioned parallel contracts. A preliminary design of the turbopump package from one of these studies is shown in Fig. 21. The turbopump consists of a two-stage centrifugal liquid methane pump which is driven directly by a single stage partial admission impulse turbine, and a single stage centrifugal FLOX pump that is geared from the fuel pump-turbine shaft through an idler at a gear reduction of $2: 1$. The turbomachines required for the engine are very small; the fuel pump impeller diameter being only $2.18 \mathrm{in}$. and the oxidizer pump impeller, 2.52 in. The turbine rotor mean diameter is 3 in. with a blade height of 0.34 in.

Comparison of the FLOX pump shown in Fig. 21 with the fluorine pump in Fig. 20 reveals one important difference, the FLOX pump has a bearing located just behind the impeller running in FLOX, whereas in the fluorine (RL10) pump the bearings are behind the seal package and are lubricated by fuel. In the smaller FLOX pump, the clearances between the rotating impeller and the housing must be very small in order to prevent excessive recirculation leakage flow, which would reduce performance. The location of this bearing near the impeller helps to reduce excessive impeller side motion and, therefore, allows close tolerances without rubbing. The bearing locations are also dictated by critical speed requirements for the shaft.

Very little work had been done in the past on fluorine lubricated bearings but the need for this technology was evident. Lewis initiated a program in 1967 to evaluate bearing cage materials that would be compatible with fluorine and have acceptably low wear rates. (31) The approach pursued was to use cage materials that were high in nickel content so that the nickel fluoride formed by reaction with fluorine would provide the necessary lubricant. This was essentially the same approach used successfully in developing fluorine pump seal materials. In the first phase of the fluorine bearings program, bearings were tested having cages of Rene'41, Hymu 80, and Berylco 440 , all of which are high in nickel content, with balls and races of $440 \mathrm{C}$ stainless steel. A typical bearing is shown disassembled in Fig. 22. Bearing tests have been made at axial loads up to $1200 \mathrm{lb}$ and DN values up to $1,000,000$ for durations up to 1 hour with acceptable cage wear rates. Under the present program, cages coated with a calcium fluoridelithium fluoride eutectic and sintered cages impregnated with $\mathrm{CaF}_{2}$ and LiF will be evaluated, in addition to the above three materials. The fluorine bearings program has yielded valuable data on bearing design, has proven the feasibility of fluorine lubricated bearings, and has dispelled the earlier fear that the friction generated within a bearing would cause the materials to rapidly heat up and react violently with the fluorine.

As previously mentioned, one of the distinctive characteristics of the turbomachines for engines of this thrust class is their small size. Some of the problems of small pumps are that the losses within the pump, both mechanical and hydraulic, tend not to scale down linearly with size but, in fact, become larger with respect to pump output, thereby reducing pump efficiency. Predicting the performance of a small pump is also difficult since the magnitude of the losses may be appreciably different than anticipated. To fill in some of the technology gaps in this field, a small pump program was initiated in 1968 to evaluate both rotating and positive displacement pumps for liquid fluorine service. $(32,33)$ The pumps were designed for a 1000-1b thrust engine, which resulted in a flow rate of $12 \mathrm{gpm}$ and a discharge pressure of 1500 psia. In the first phase of this program, a 
variety of pump types were analyzed to determine the best types for this application considering performance, weight, size, and complexity. The types selected, shown in Fig. 23, were a gear type pump and a centrifugal pump. These pumps have been fabricated and are undergoing experimental evaluation.

\section{$\underline{\text { Valves }}$}

In regard to valves that are applicable to pump-fed FLOX-methane engines, the principal area requiring new technology is that of low leakage flightweight valves for fluorine or FLOX service. A great deal of work, too extensive to discuss here, has been done in the past in the fields of materials compatibility, valve design, and the like which has laid the technology groundwork for this field. More recently, programs were undertaken to investigate specific problem areas still remaining and to apply the flightweight fluorine system component design criteria that were developed to the design of a poppet-type shutoff valve. $(34,35,36)$ Following this, two programs were undertaken to fabricate and test valves of this type. $(37,38)$ These particular valves were designed as tank pre-valves, but the general design criteria could equally well be applied to an enginemounted valve. The valves are for a 2 -in. line size and were designed for low pressure drop and very low leakage (less than $1 \times 10^{-7} \mathrm{lb} / \mathrm{sec}$ of fluorine). The first of two designs being evaluated is shown in Fig. 24. In this design, a flat hard-on-hard, metal-to-metal seat and poppet (A286 CRES seat and Inconel 718 poppet) are used with the compliant seal supported by a bellows. The bellows arrangement provides for slight misalignment and maintains proper loading during thermal cycling. This valve has been tested for 800 cycles in liquid fluorine and the leakage was within specifications.

The second valve design being evaluated employs a conical seat of Inconel 718 and a hemispherical, goldplated poppet of 304L stainless steel. This design also allows for misalignment of the poppet and seat and uses a stop to limit deflection of the poppet during seating. An alternate poppet material, beryllium nickel 440 , will also be evaluated.

Other related work on flightweight fluorine valves was done under the hydrogen-fluorine RL10 program $(27,28)$ and the FLOX-methane RL10 program. (10) In these programs, the engine liquid oxygen system valves were modified for use in fluorine or FIOX. Two valves were so modified: the inlet valve and the mixture ratio control valve. The modifications included changes of the body seals and the dynamic seals to eliminate polymeric materials and substitute metal-tometal seals. These modifications were successfully made and the measured leakages were within RL10 engine specifications for these valves.

\section{Application of Technology}

A program has been initiated at Lewis within the last year to demonstrate the application of both enginerelated and vehicle-related technology for stages designed for long space coast missions. In this Research
Propulsion Module program, simulated stages for both FLOX-methane and hydrogen-fluorine propellants will be built up and tested. The objectives of this program are to investigate systems problems related to the design, fabrication, and operation of a stage specifically designed for missions requiring coast times in space for up to 4 years, to demonstrate the feasibility of developing such a stage, and to provide comparative data on the two propellant combinations so that an intelligent selection may be made for such a stage development.

The general configuration of the FLOX-methane propulsion module is shown in Fig. 25. The module will consist of a space truss structure within which will be mounted flightweight fuel and oxidizer tanks. The truss members will be stainless steel tubes with preferential coatings to control radiation, and the tank material will be 2219-T62 aluminum. The tanks will be covered with multilayer insulation consisting of double aluminized Mylar with silk net spacers. The tanks will be supported by fiberglass struts designed to reduce heat leak into the tanks. The hydrogen-fluo rine module will have shadow shields located between the payload and fuel tank to reduce radiation heat transfer. Complete propellant flow systems, including all valves and lines, and the tank pressurization system will be installed. For the FLOX-methane stage, a 5000-lb thrust, pump-fed, regeneratively-cooled engine will be procured. This will be a "research" engine that will be built up based on the available technology as described in this paper. The engine will be extensively tested prior to use on the module to demonstrate its performance and reliability, but will not be in any sense a fully developed engine.

Both modules, minus engine, will be tested in the K-site facility at Lewis' Plum Brook Station to ascertain thermal and fluid system performance. Ground hold, boost, and space hold tests will be conducted with simulated space hold being achieved by the use of liquid hydrogen cold walls and hard vacuum. Heat flux will be measured over long periods of time using liquid methane or hydrogen in the fuel tank, liquid nitrogen in the oxidizer tank, and with a simulated payload at $520^{\circ} \mathrm{R}$. Following this, the complete module, including engine in the FLOX/methane case, will be tested in the B-2 facility at Plum Brook. This facility has the capability for space simulation and engine firing, so that a complete mission may be simulated in all aspects except zero gravity. Completion of this program will provide valuable criteria for a space storable stage and will obtain useful experience on handling of a complete stage containing a fluo rinated oxidizer.

\section{Conclusions}

A summarization of the status of the FLOXmethane pump-fed engine technology may best be made by considering the various specific areas discussed herein.

1. Injectors - For a fixed thrust engine utilizing regenerative cooling wherein the injector uses gas/liquid propellants, the concentric tube type injector is the most promising. It provides excellent performance of 
the order of 98 percent C* efficiency, good durability, and provides acceptable heat transfer to the thrust chamber. For a throttling injector, additional work is needed to select an optimum design.

2. Thrust Chamber - Sufficient data have been obtained to prove the feasibility of regenerative cooling at chamber pressures of 500 psia. Chamber designs utilizing coolant channels, rather than tubes, and conductive materials, such as nickel rather than stainless steel, are necessary because of the high heat flux and small flow passages required. A variety of advanced fabrication methods are available that are suitable for such chambers.

3. Performance - Delivered specific impulse values up to 396 sec have been demonstrated for a nozzle area ratio of 60 , chamber pressure of 500 psia, and $O / F$ of 5.0 to 5.5. Nozzle kinetic losses are, therefore, demonstrated to be no greater than 1 to 2 percent at these conditions.

4. Engine Cycle - The expander cycle appears to be optimum for a small pump-fed FLOX-methane engine. This provides maximum performance, a clean turbine working field, and simple system design. Turbine power margin is about 25 percent, which provides ample margin for changes of heat transfer or component efficiencies.

5. Turbomachinery - An engine of this type requires turbomachines that are quite small and rotate at high speeds, but which are otherwise conventional in design. For the FLOX pumps, technology on materials for rubbing shaft seals and fluorine lubricated bearings has been developed. Work on small pumps for fluorine is proceeding to provide additional design criteria, thereby making prediction of pump efficiency more reliable.

6. Valves - A number of valves of different types have been tested in fluorine. The use of metal-to-metal seat and poppet is necessary to eliminate problems associated with noncompatibility of polymeric materials with fluorine or FLOX. Very low leakage rates have been demonstrated. Completely acceptable operation of flightweight methane and fluorine valves in actual pump-fed engine firings has been amply demonstrated.

\section{Nomenclature}

C* characteristic exhaust velocity, $\mathrm{ft} / \mathrm{sec}$

F thrust, lbf

$I_{\mathrm{sp}} \quad$ specific impulse, $\mathrm{lbf}-\mathrm{sec} / \mathrm{lbm}$

L* chamber characteristic length; in.

$\mathrm{P}_{\mathrm{c}} \quad$ chamber pressure, psia

$Q_{m} / Q_{p}$ ratio of experimentally measured-totheoretically predicted thrust chamber heat transfer

$r$ oxidizer-to-fuel mixture ratio $(O / F)$ $\epsilon_{c} \quad$ chamber contraction ratio

$\epsilon_{\mathrm{e}} \quad$ nozzle expansion ratio

\section{$\underline{\text { References }}$}

1. Stephenson, F. W., Jr., "A Survey of NASA/OART Space Storable Propulsion Programs, " Paper 68613, June 1968, AIAA, New York, N. Y.

2. Johnson, V. L. and Davis, B. W., "Present Needs, Capabilities, and Future Prospects in Rocket Technology for Space Research, "Space Science Reviews, Vol. 8, No. 2, Apr. 1968, pp. 139-213.

3. Anon., "Propellant Selection for Unmanned Spacecraft Propulsion Systems. Vol. 1: Results, Conclusions, and Recommendations, Phase 2," K-21-69-9-vol. 1, NASA CR-105201, Sept. 1969, Lockheed Missiles and Space Co., Sunnyvale, Calif.

Vo1. 2: Analysis of Propellant Sensitivity, Secondary Propulsion, and Ground Operations, Phase 2," K-21-69-9-vol. 2, NASA CR105202, Sept. 1969, Lockheed Missiles and Space Co., Sunnyvale, Calif.

Vol. 3: Study of Propulsion Stage Commonality and Attitude Control Systems Requirements, Phase 2, "K-21-69-9, vol. 3, NASA CR105203, Sept. 1969, Lockheed Missiles and Space Co. , Sunnyvale, Calif.

4. Oglebay, J. C., Sagerman, G. D., and Valentine, H. H., "Analytical Evaluation of Space Storable Propellants for Unmanned Jupiter and Saturn Orbiter Missions," TM X-1793, 1969, NASA, Cleveland, Ohio.

5. Mitchell, J. P. and Kaminski, W. R., "Space Storable Regenerative Cooling Investigation, " Paper 68-616, June 1969, AIAA, New York, N. Y.

6. Mitchell, J. P., "Space Storable Regenerative Cooling Investigation, " PWA-FR-2552, NASA CR72341, Apr. 1968, Pratt \& Whitney Aircraft, West Palm Beach, Fla.

7. Pauckert, R. P., "Space Storable Regenerative Cooling Investigation, " R-7338, NASA CR-72360, Sept. 1968, Rocketdyne Div., North American Rockwell, Canoga Park, Calif.

8. Burry, R. V. and Pauckert, R. P., "Engine System Design for Space Storable Propellants, " Paper 68-615, June 1968, AIAA, New York, N. Y.

9. Mitchell, J. P. and Neal, J. W., "Space Storable Regenerative Cooling Investigation, " Paper 69-509, June 1969, AIAA, New York, N.Y.

10. Colbert, J. W., Mosier, S. A., and Bailey, T. E., "FLOX/Methane Pump-Fed Engine Study," PWAFR-3040, NASA CR-72485, May 1969, Pratt \& Whitney Aircraft, West Palm Beach, Fla. 
11. Masters, A. I., Colbert, J. E., and Brooke, A. W., "FIOX/Methane Pump-Fed Engine Systems," Paper 69-510, June 1969, AIAA, New York, N.Y.

12. Mitchell, J. P., "Space Storable Regenerative Cooling Investigation, " NASA CR-72704, to be published.

13. Pauckert, R. P., "Space Storable Regenerative Cooling Investigation, "NASA CR-72705, to be published.

14. Mehegan, P., "Investigation of Gas Annealed Injectors," NASA CR-72703, to be published.

15. Falk, A. Y., Clapp, S. D., and Nagai, C. K. "Space Storable Propellant Performance Study," NASA CR-72663, to be published.

16. Falk, A. Y., Clapp, S. D., and Nagai, C. K. "Space Storable Propellant Performance Study," R-7677, NASA CR-72487, Nov. 1968, Rocketdyne Div., North American Rockwell, Canoga Park, Calif.

17. Burry, R. V., "Space Storable Engine Characterization, "R-7879, NASA CR-72559, Mar. 1970, Rocketdyne Div., North American Rockwell Corp., Canoga Park, Calif.

18. Masters, A. I., Brooke, A. W., and Bailey, T. E., "Space Storable Engine Characterization," PWAFR-3169, NASA CR-72552, Nov. 1969, Pratt \& Whitney Aircraft, West Palm Beach, Fla.

19. Bittker, D. A., "Comparison of Experimental and Kinetically Limited Theoretical Performance of the Hydrogen-Fluorine Propellant System, " TN D-3607, 1966, NASA, Cleveland, Ohio.

20. Waldman, B. J. and Shuster, E. B., "FluorineHydrogen Performance Evaluation. Phase I, Part II: Nozzle Performance Analysis and Demonstration, " R-6636-2, NASA CR-72038, Apr. 1967, Rocketdyne Div., North American Rockwell, Canoga Park, Calif.

21. Sarli, V. J., Burwell, W. G., and Zupnik, T. F., "Investigation of Nonequilibrium Flow Effects in Hydrogen-Fluorine Rocket Nozzles, "' VARLE910370-13, NASA CR-72162, Sept. 1966, United Aircraft Corp., East Hartford, Conn.

22. Sarli, V. J., et al.: Investigation of Nonequilibrium Flow Effects in Hydrogen-Fluorine Rocket Nozzles. NASA CR-72347, Dec, 1967.

23. Bittker, D. A., "Nonequilibrium Calculations of Methane Fluorine Oxygen and Butene-1-Fluorine Oxygen Rocket Performance," TN D-4991, 1969, NASA, Cleveland, Ohio.
24. Sarli, V. J., Bender, L. S., Aceto, L. D., and Burwell, W. G., "Kinetic Flow Performance in Nozzles, " VARL-H910666-15, NASA CR-72600, United Aireraft Corp., East Hartford, Conn.

25. Bender, L. S., Sarli, V. J., and Burwell, W. G., "NASA Kinetic Performance Handbook," NASA CR-72601, to be published.

26. Waldman, B. J., "Space Storable Propellant Performance Demonstration," NASA CR-72542, to be published.

27. Bailey, T. E., "Research on a Hydrogen-Fluorine Propulsion System," PWA-FR-1585, NASA CR72074, Oct. 1966, Pratt \& Whitney Aircraft, West Palm Beach, Fla.

28. Munk, W. R. and Bailey, T. E., "HydrogenFluorine Engine Evaluation, " PWA-FR-3030, NASA CR-72481, Oct. 1969, Pratt \& Whitney Aircraft, West Palm Beach, Fla.

29. Hady, W. F., Allen, G. P., Sliney, H. E., and Johnson, R. L., "Friction, Wear, and Dynamic Seal Studies in Liquid Fluorine and Liquid Oxygen." TN D-2453, 1964, NASA, Cleveland, Ohio.

30. Osborn, W. M. , "Investigation of a Liquid-Fluorine Inducer and Main-Stage Pump Combination Designed for a Suction Specific Speed of 20,000," TM X-1070, 1965, NASA, Cleveland, Ohio.

31. Mallaire, F., "Fluorine Lubricated Bearings, Vol, I: Cage Material Evaluation - NASA CR72683; Vol. II: Bearing Test Results - NASA CR72684, to be published."

32. MacGregor, C. A., "Rotating and Positive Displacement Pumps for Low Thrust Rocket Engines, Vol. I: Comparative Evaluations," NASA CR72685 , to be published.

33. Csomer, A., "Rotating and Positive Displacement Pumps for Low Thrust Rocket Engines. Vol. II: Design Data and Test Results," NASA CR-72686, to be published.

34. Anon., "Development and Demonstration of Criteria for Liquid Fluorine Feed System Components, " DAC-60599, NASA CR-72063, Oct. 1967, Douglas Aireraft Co., Santa Monica, Calif.

35. Anon., "Fluorine Systems Handbook, " DAC59074, NASA CR-72064, July 1967, Douglas Aircraft Co., Santa Monica, Calif.

36. Endicott, D. L. and Donahue, L. H., "Development and Demonstration of Criteria for Liquid Fluorine Feed System Components, " DAC-63240, NASA CR-72543, June 1969, McDonnell-Douglas Astronautics Co., Huntington Beach, Calif.

37. Endicott, D. L., "Space Storable Oxidizer Valve," NASA CR-72690, to be published. 
38. Crosier, R. L. and Goodman, O. D., "Space

Sto rable Oxidizer Valve," NASA CR-72691, to be published.

39. Dickerson, R. A., Tate, K. W., and Barsec, N. J., "Correlation of Spray Injector Parameters with Rocket Engine Performance, " R-7499, AFRPLTR-68-147, AD-839979, June 1968, Rocketdyne Div., North American Rockwell, Canoga Park, Calif.

TABLE 1 ENGINE CHARACTERISTICS

\begin{tabular}{|l|l|}
\hline Propellants: & $\begin{array}{l}\text { Liquid Methane } \\
\text { Liquid FLOX (82.6 percent } \\
\text { by weight fluorine) } \\
5000 \mathrm{lb}\end{array}$ \\
Thrust: & $500 \mathrm{psia}$ \\
Chamber Pressure: & 60 \\
Nozzle Area Ratio: & Regenerative \\
\hline Chamber Cooling Mode: & Reg \\
\hline
\end{tabular}

TABLE 2 ENGINE DESIGN POINTS

\begin{tabular}{|l|c|c|}
\hline & I & II \\
\cline { 2 - 3 } Thrust, lb & 5000 & 5000 \\
Chamber Pressure, psia & 800 & 500 \\
Mixture Ratio, O/F & 5.25 & 5.25 \\
Nozzle Area Ratio & 100 & 60 \\
\hline
\end{tabular}

TABLE 3 FLOX-METHANE ENGINE OFF-DESIGN POINT OPERATION ${ }^{2}$

\begin{tabular}{|l|lll|ll|l|l|}
\hline Chamber Pressure - psia & 500 & 500 & 500 & 500 & 500 & 800 & 50 \\
Mixture Ratio & 5.25 & 5.25 & 5.25 & 4.75 & 5.75 & 5.25 & 5.25 \\
$\mathrm{Q}_{\mathrm{m}} / \mathrm{Q}_{\mathrm{p}}$ (Heat Flux Ratio) & 0.9 & 0.76 & 1.0 & 0.9 & 0.9 & 0.9 & 0.9 \\
Turbine Bypass Flow, percent & 25 & 22 & 28 & 25 & 25 & 10 & 58 \\
Turbine Speed - rpm & 50,500 & 49,950 & 50,850 & $\mathbf{5 2 , 4 7 0}$ & 49,210 & 68,000 & 12,960 \\
Turbine Inlet Temperature, ${ }_{\mathrm{R}}$ & 1415 & 1273 & 1511 & 1338 & 1487 & 1340 & 1729 \\
Fuel Pump Discharge Pressure - psia & 1231 & 1201 & 1250 & 1300 & 1186 & 2053 & 124 \\
Oxidizer Pump Discharge Pressure - psia & 646 & 630 & 656 & 704 & 607 & 1058 & 85 \\
\hline
\end{tabular}

asingle turbine, gear drive turbomachinery arrangement. 


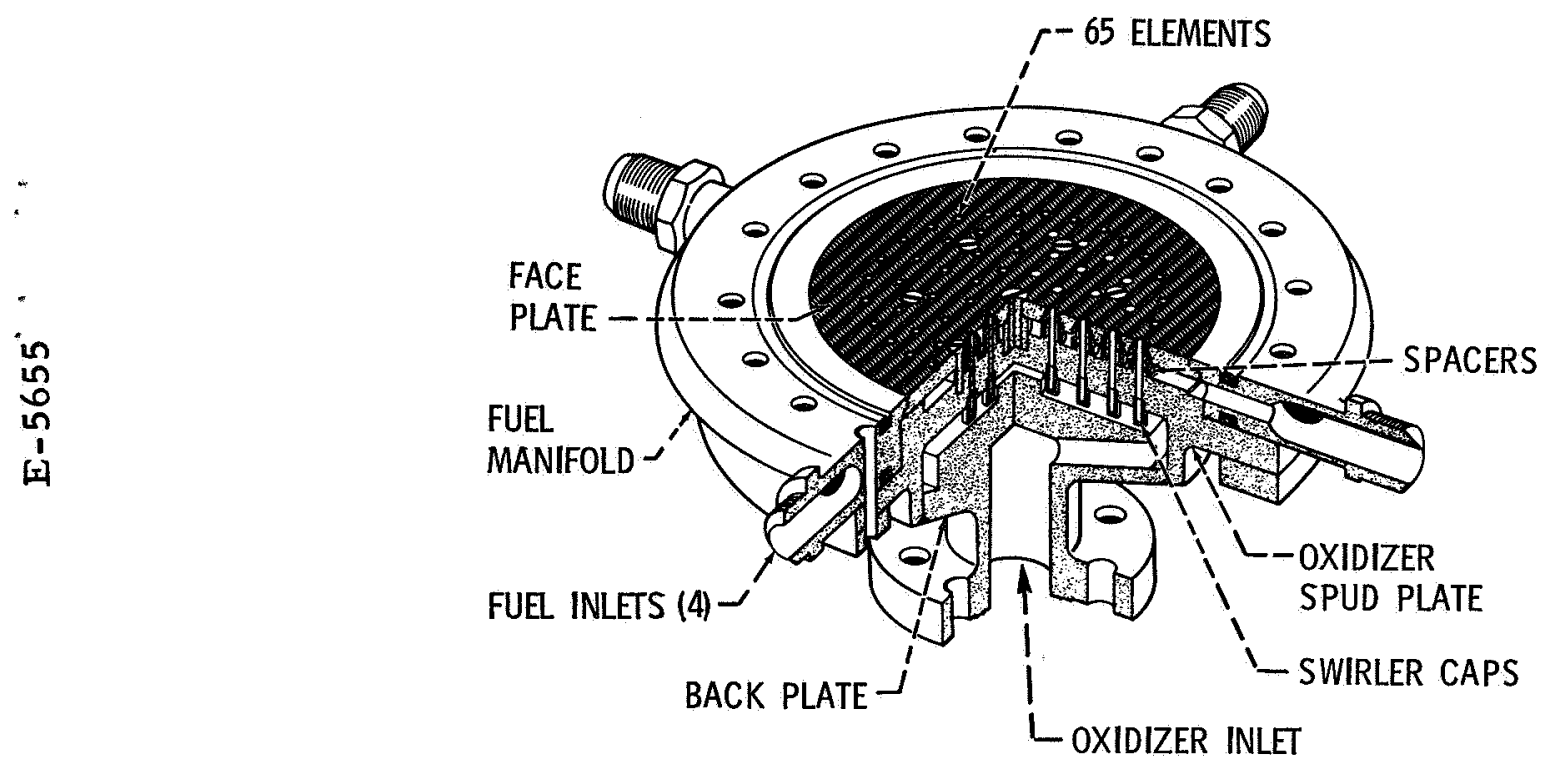

Figure 1. - 5K FLOX/methane concentric injector.

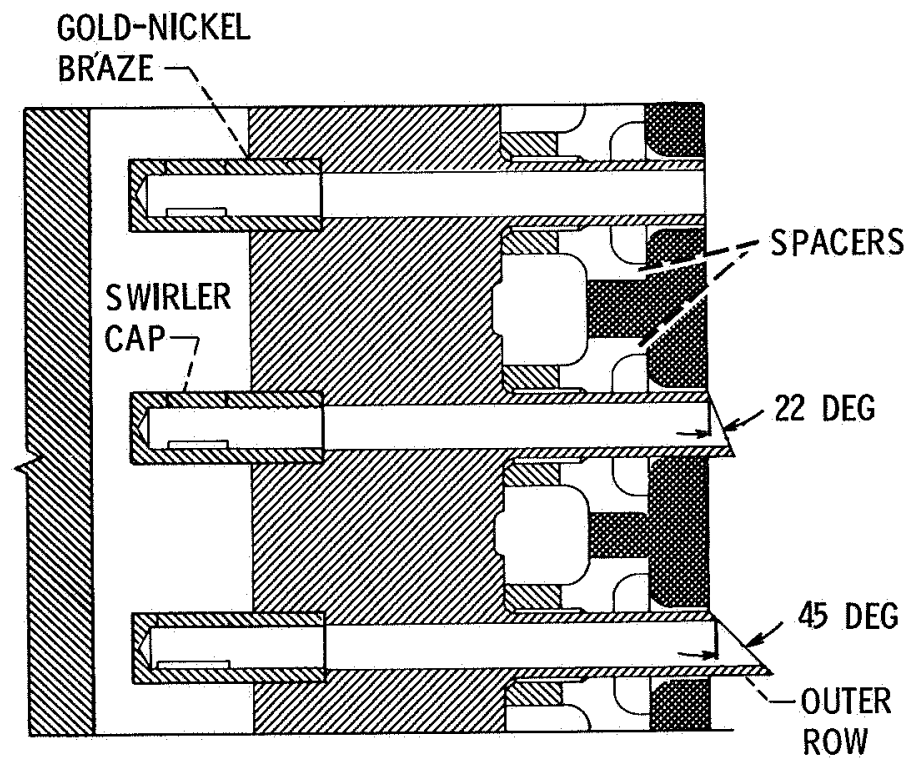

Figure 2. - $5 \mathrm{~K}$ FLOX/methane scarfed-element injector detail. 


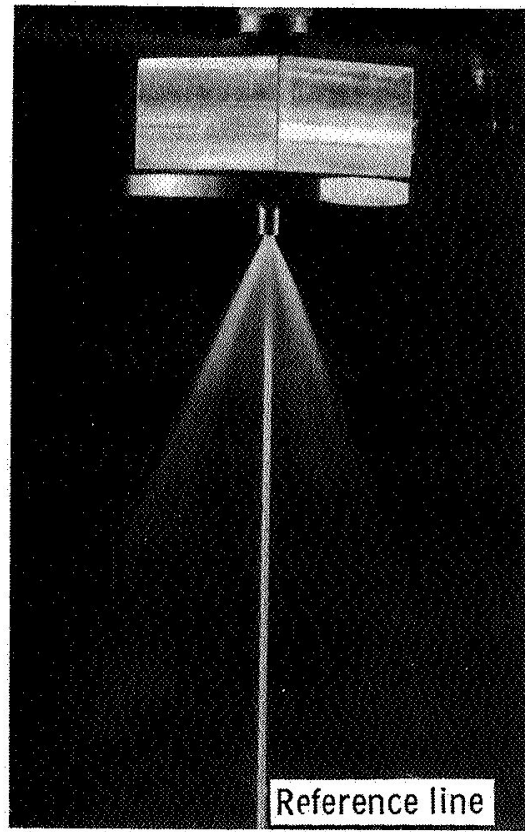

Unscarfed spud spray pattern

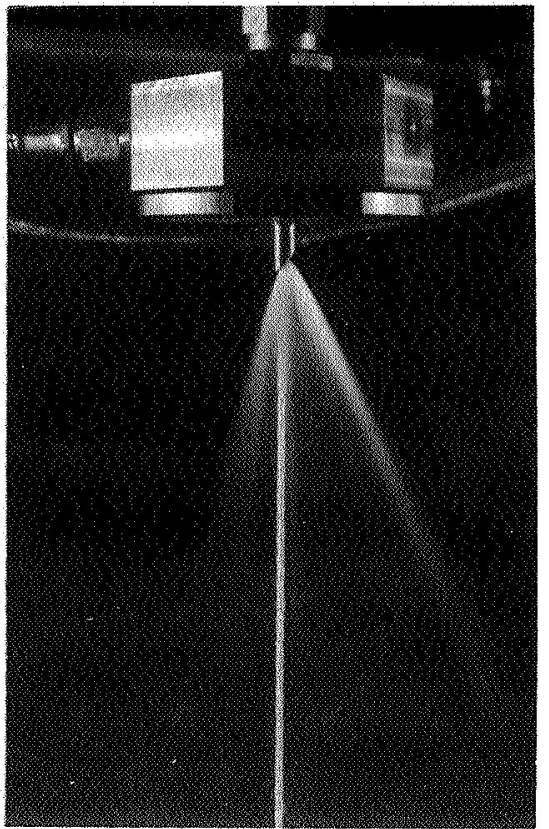

45-degree scarfed spud spray pattern

Figure 3. - Comparison of scarfed and unscarfed element spray patterns.

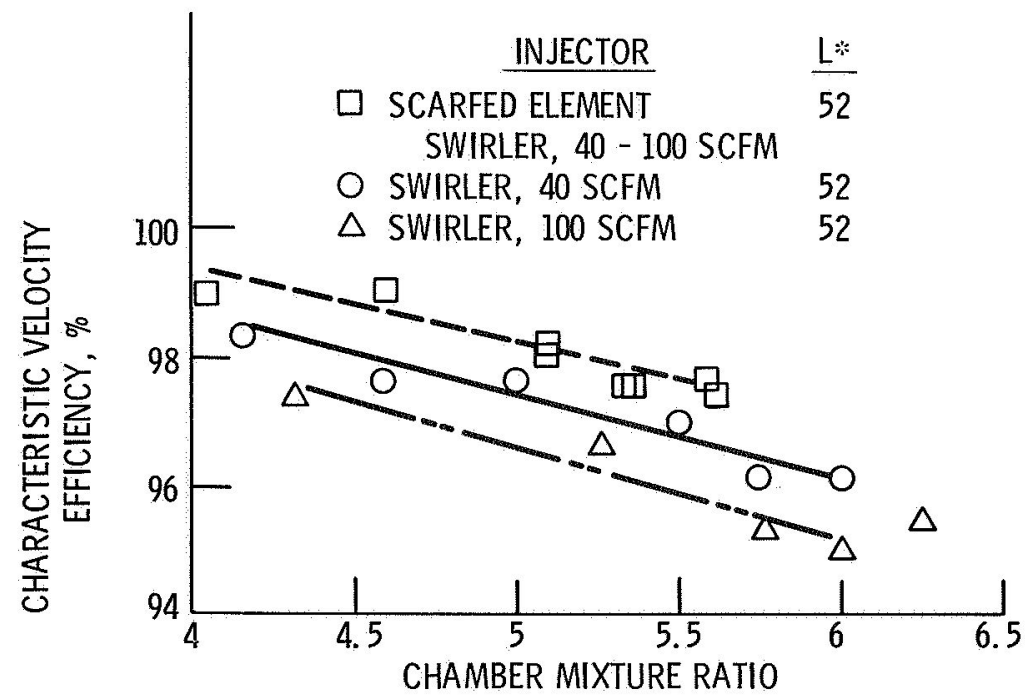

Figure 4. - FLOX/methane concentric tube injector performance data. 


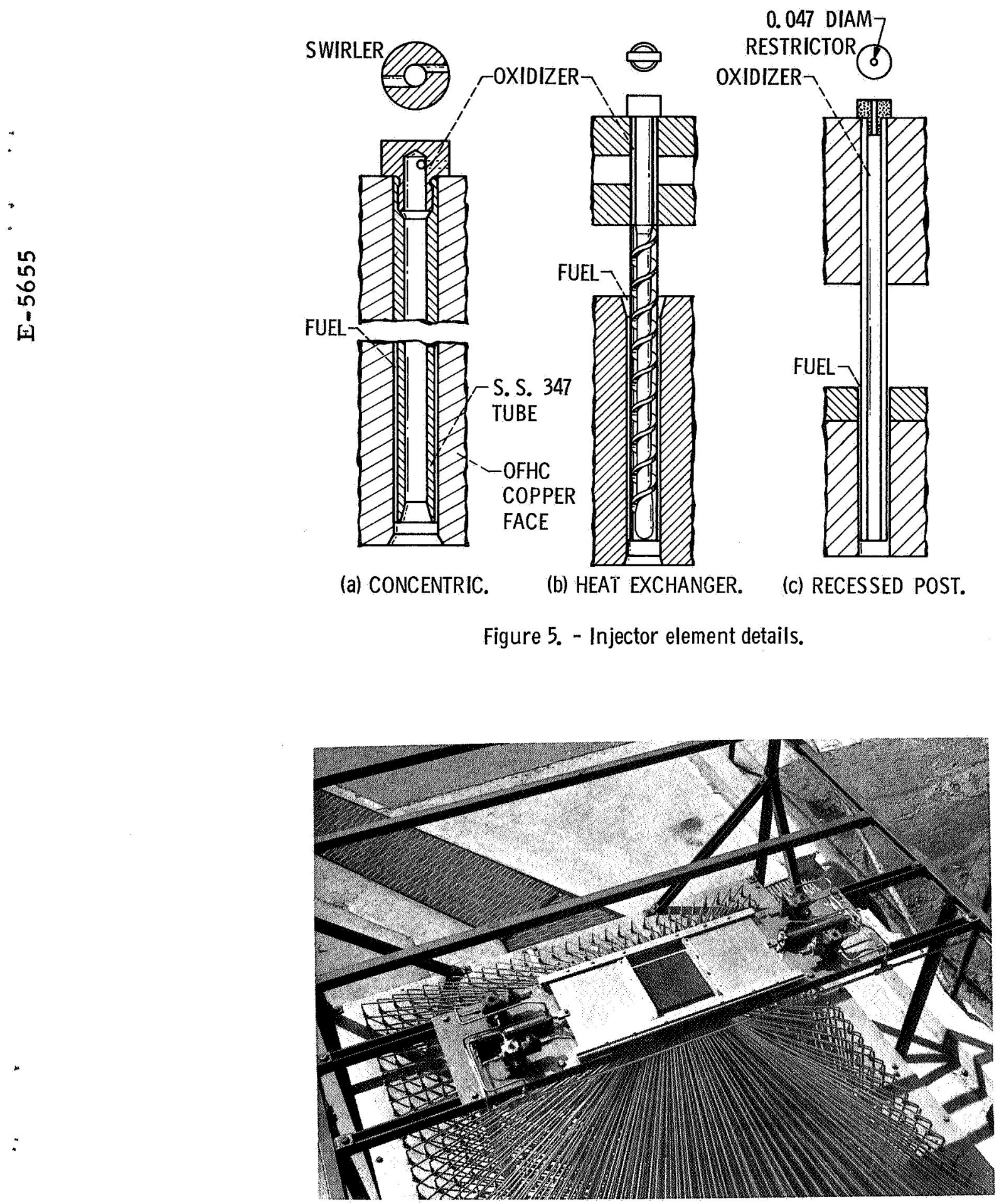

Figure 6. - Spray collector grid and shutter arrangement of injector spray collection system. 

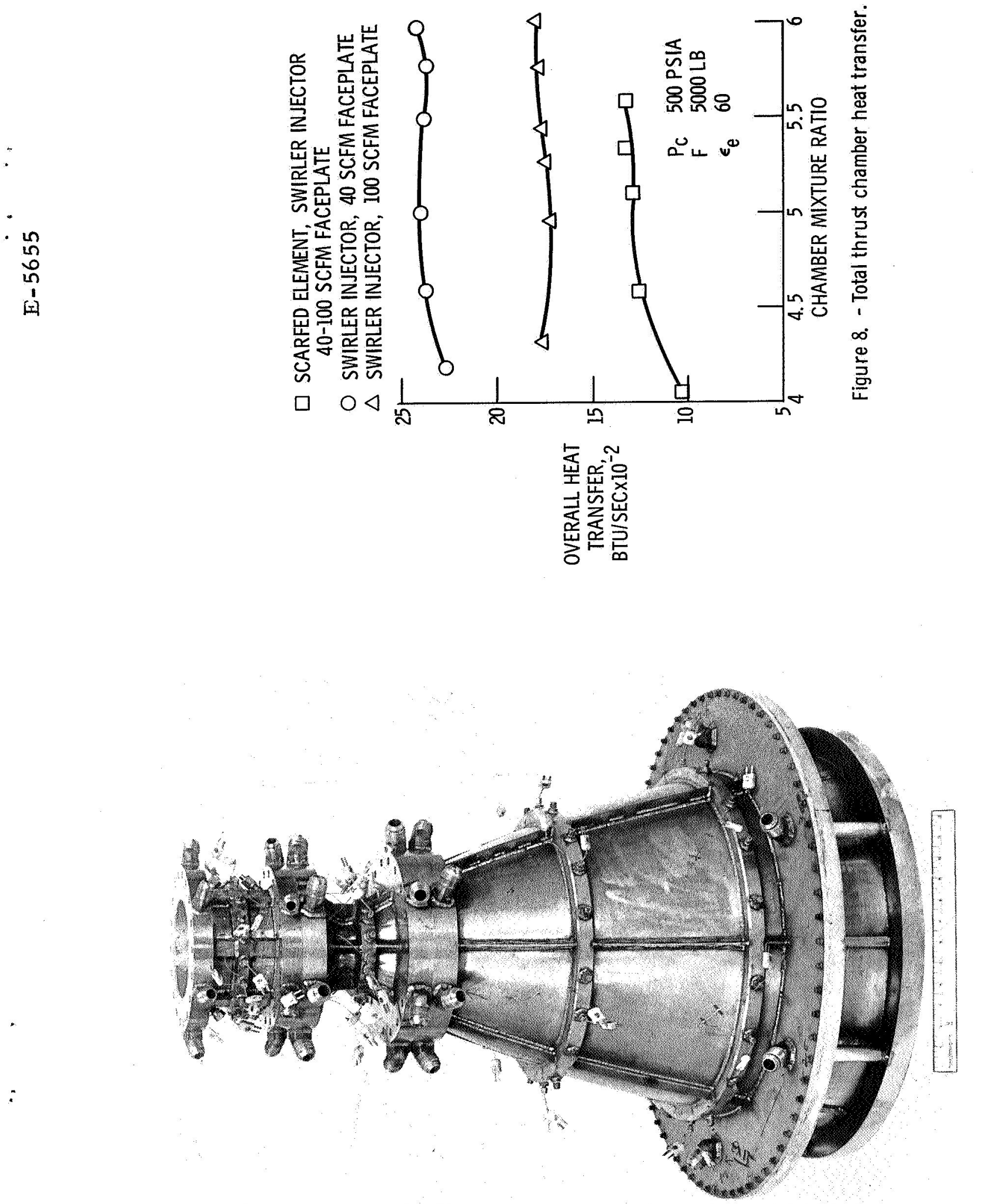

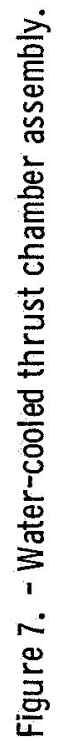



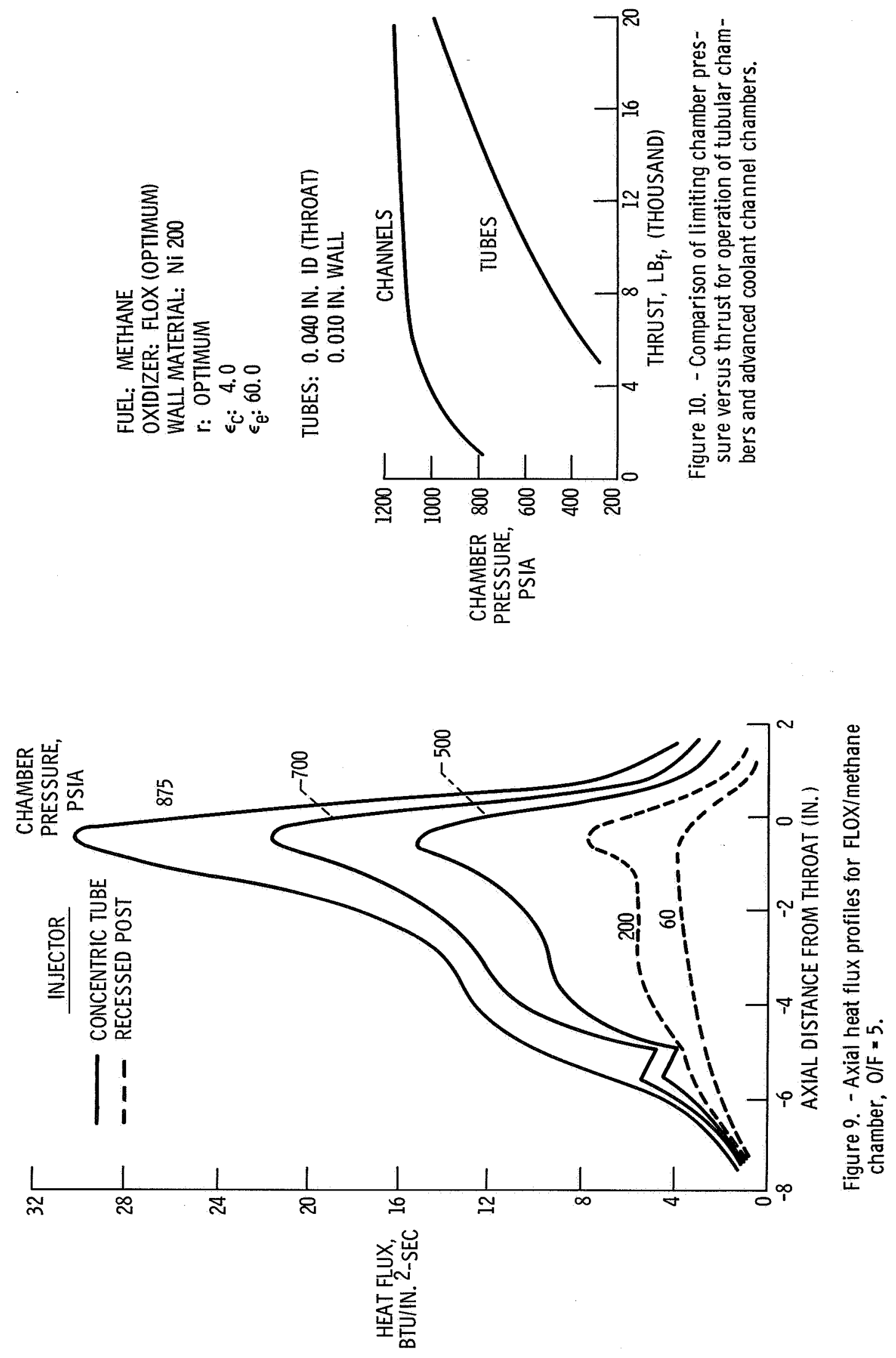


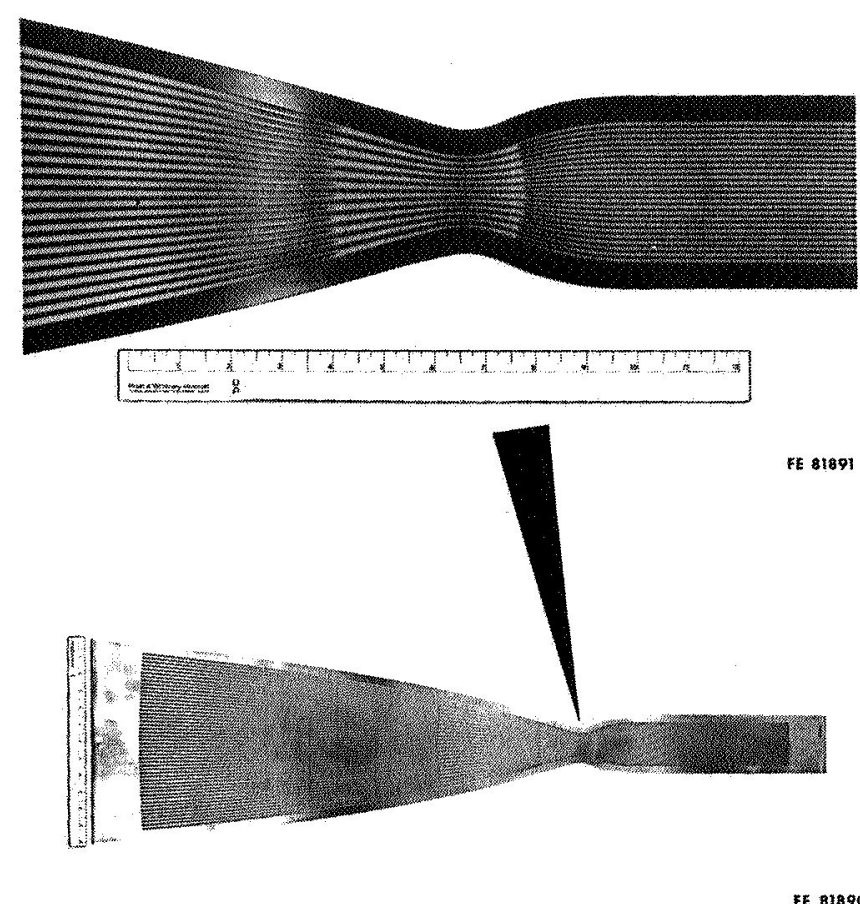

Figure 11. - Engraved nickel plate for $5 \mathrm{~K}$ flox/methane thrust chamber.

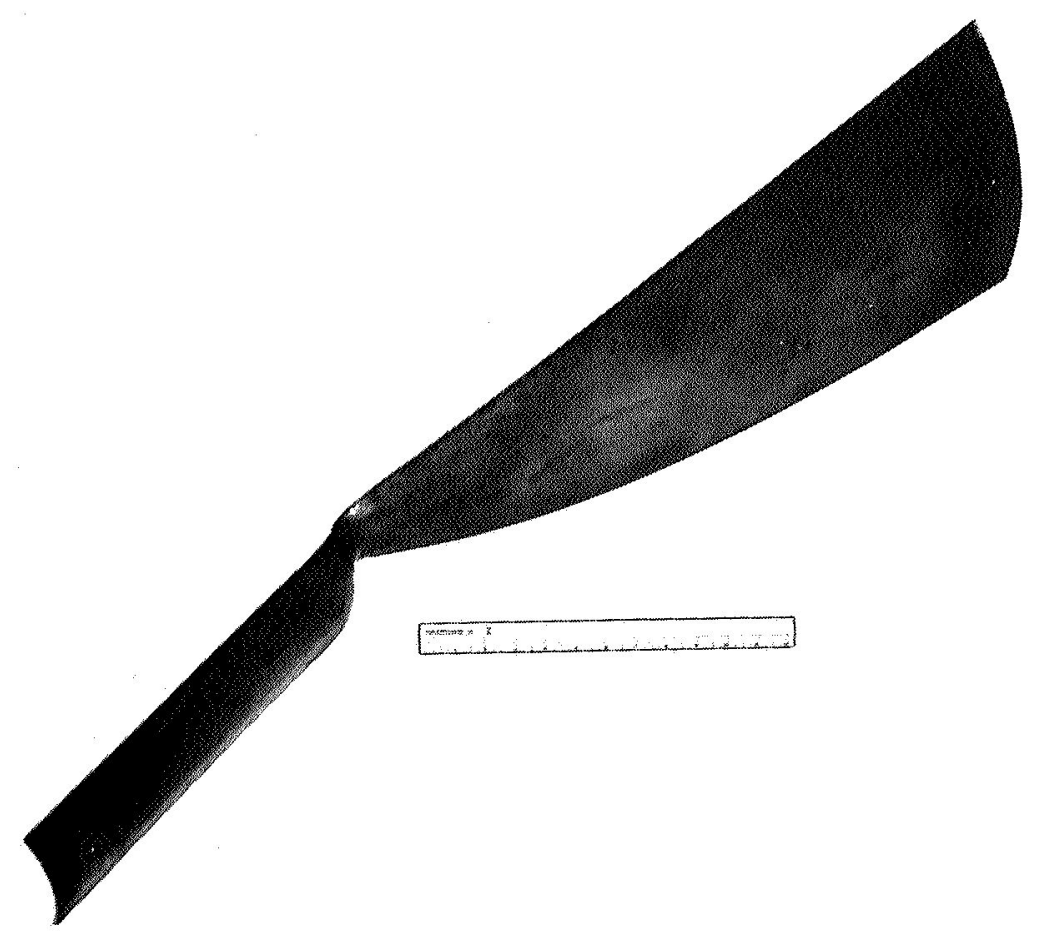

Figure 12. - Thermal $S_{k i n_{R}}$ chamber segment. 

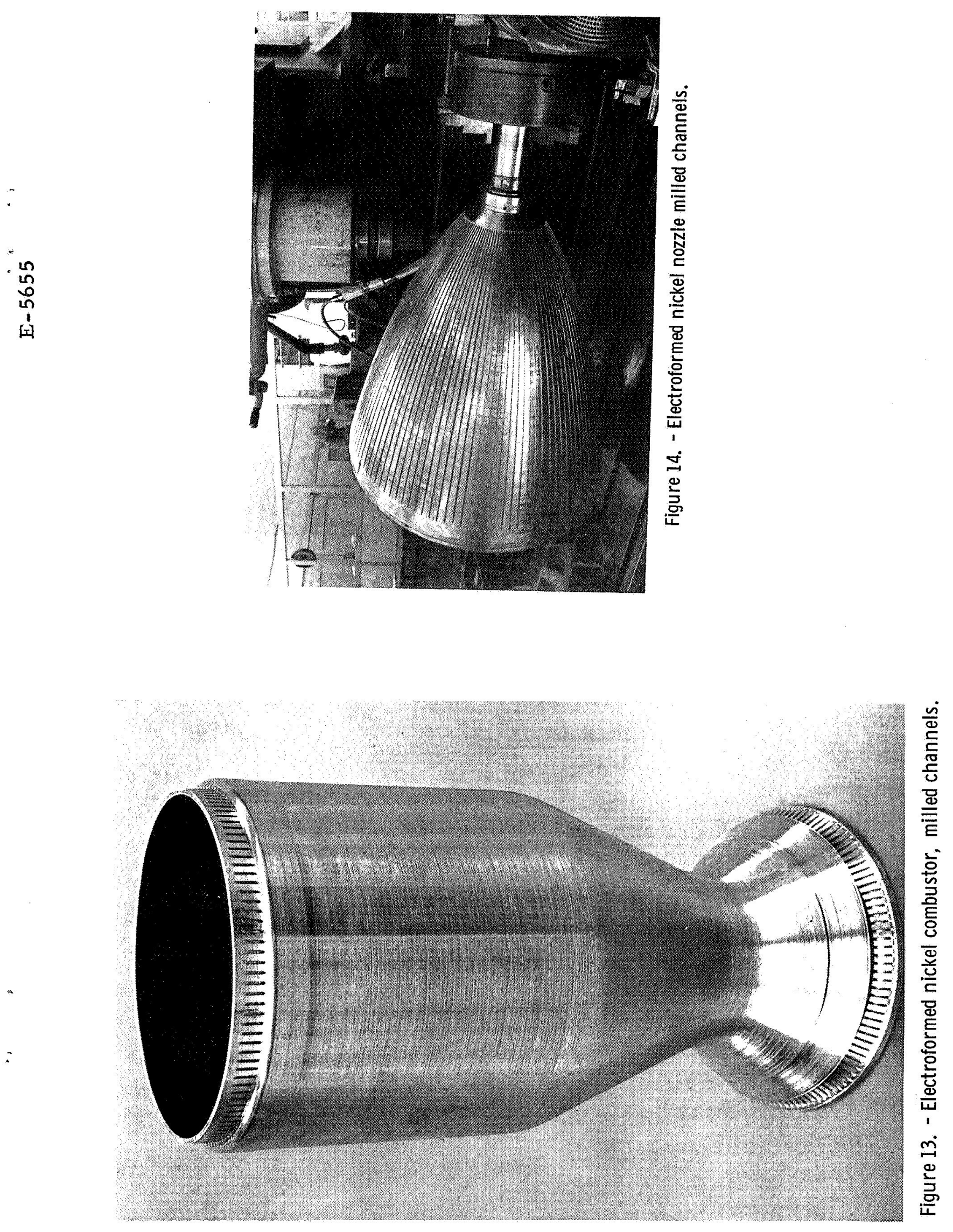

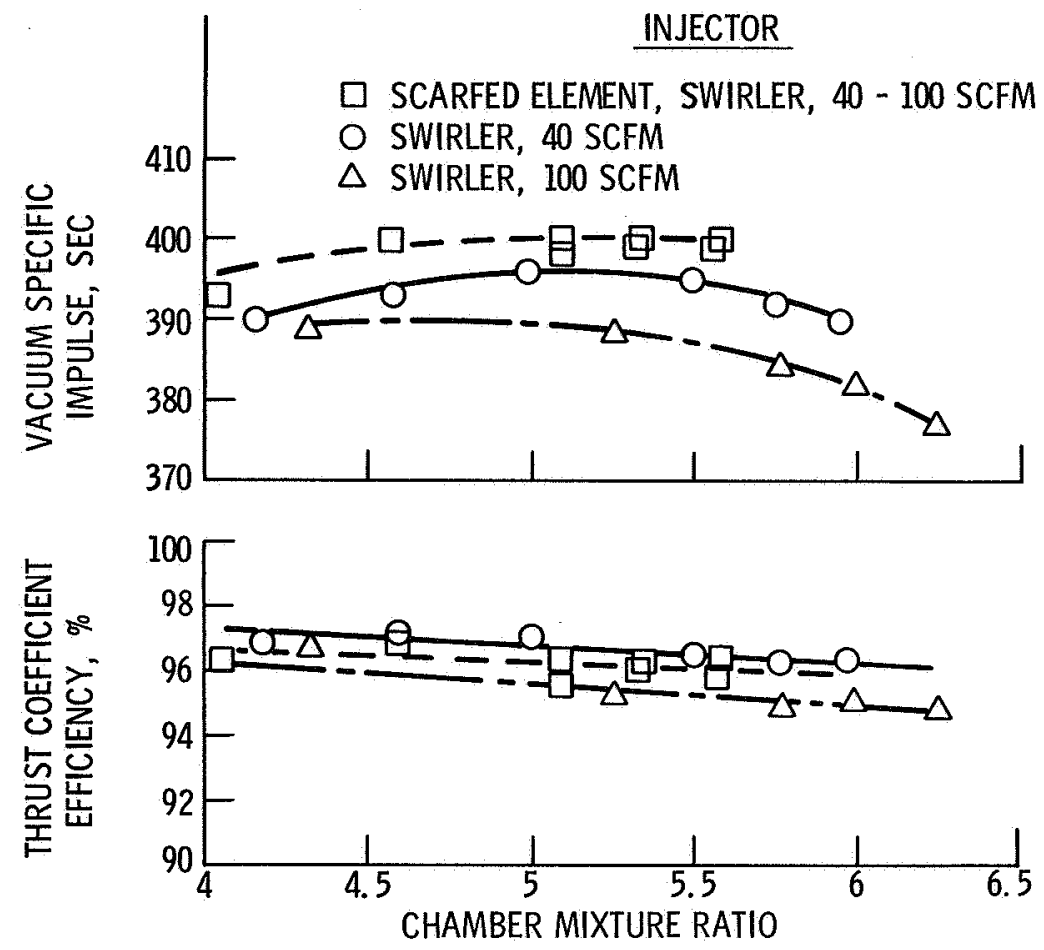

Figure 15. - Altitude performance comparison $5 \mathrm{~K}$ FLOXI methane thrust chamber. $P_{C}=500$ psia, $\epsilon_{e}=60$, $L^{* *}=52$.

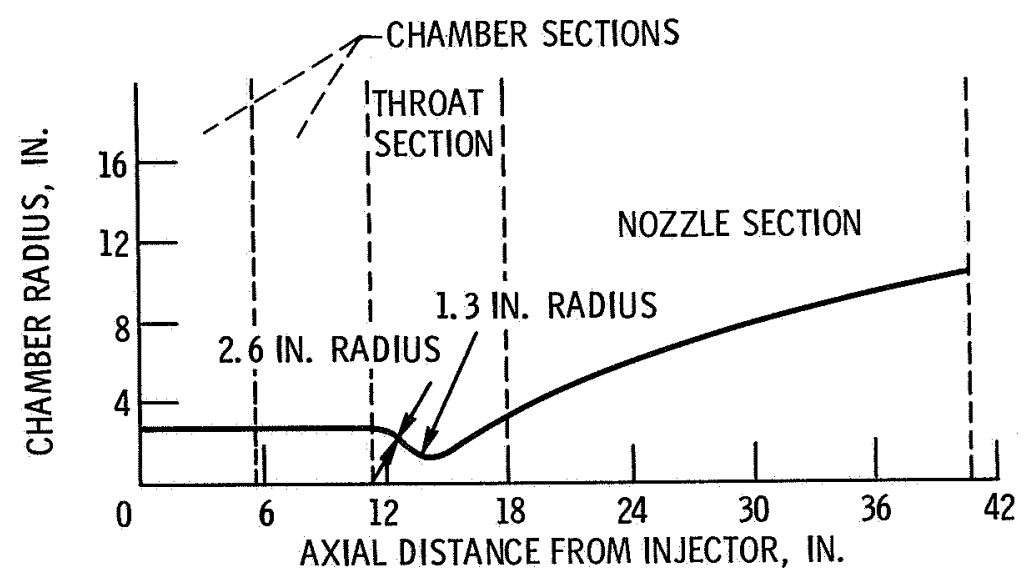

Figure 16. - Thrust chamber contour. 

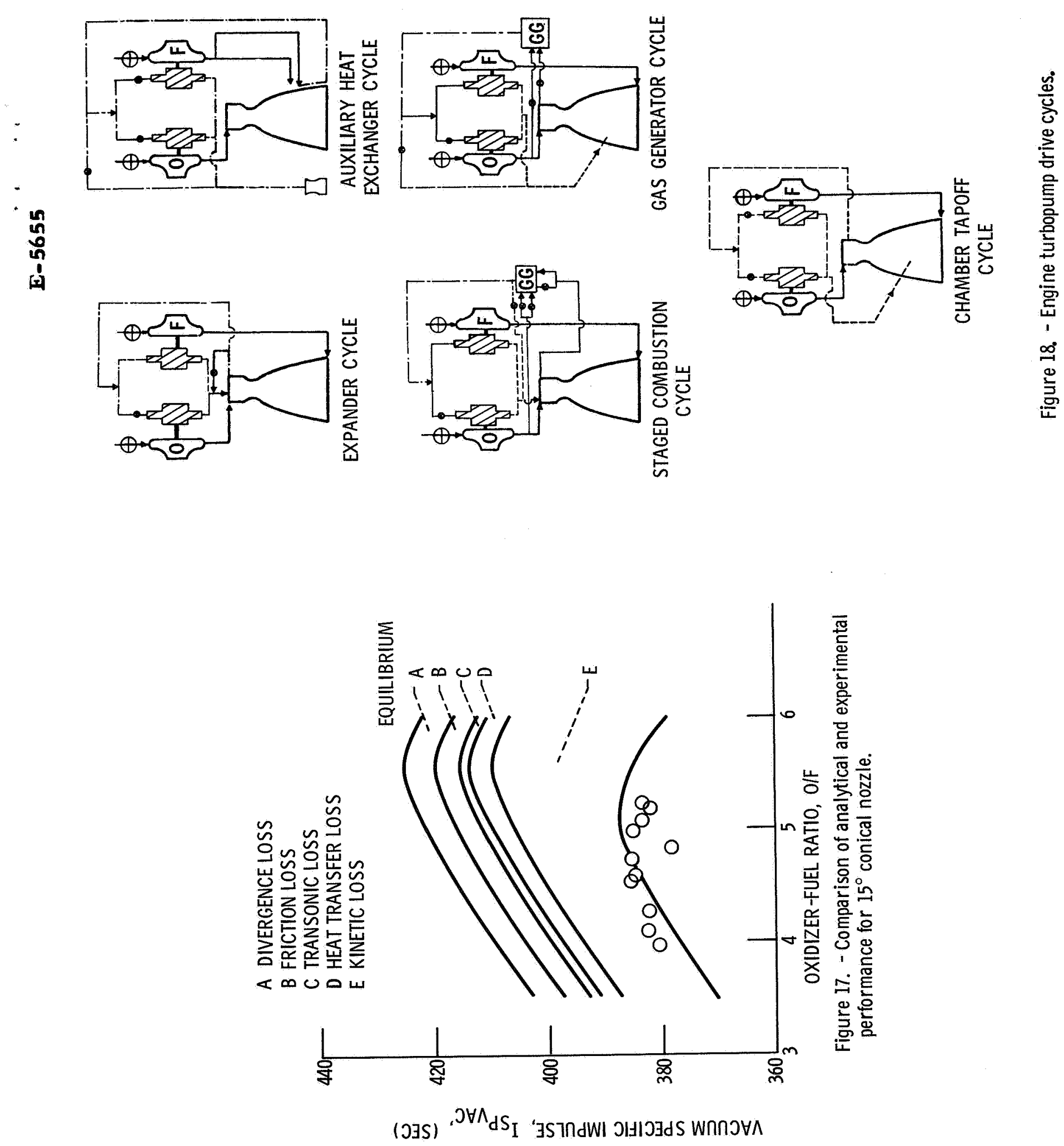


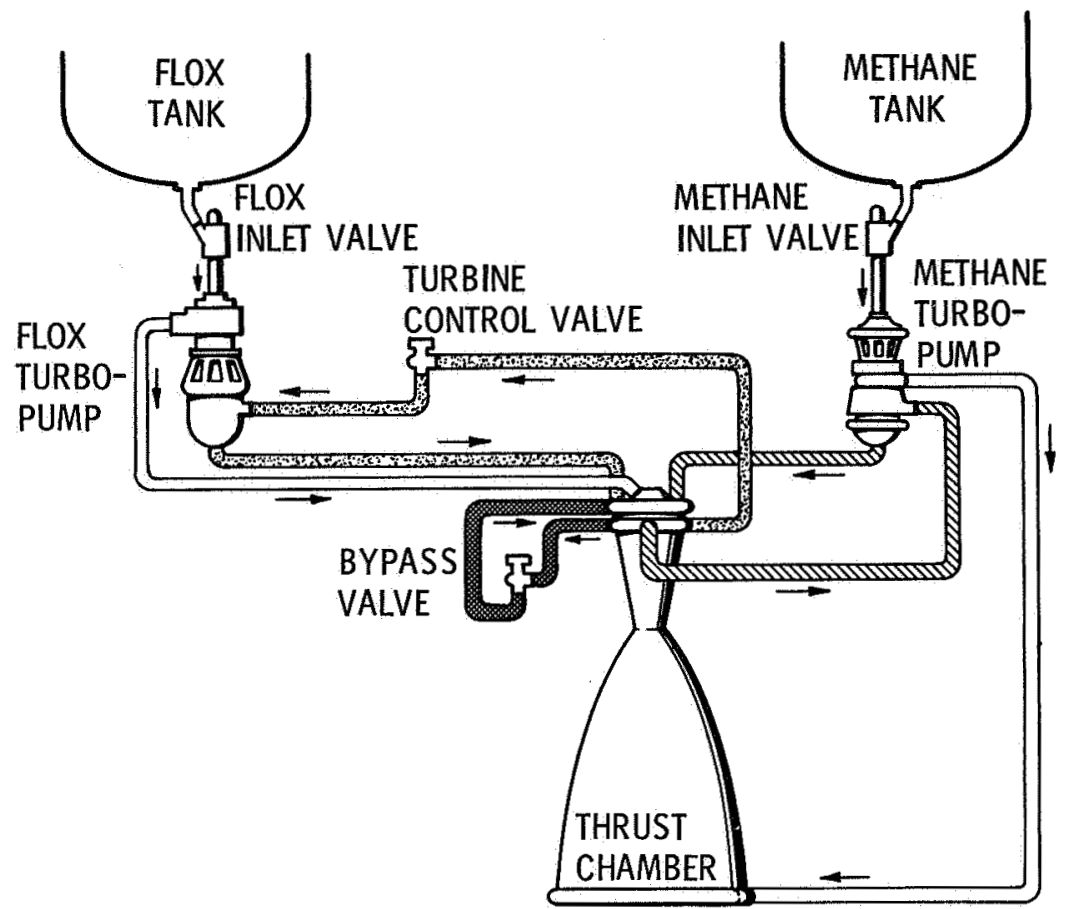

Figure 19. - 5K FLOX/methane engine schematic.

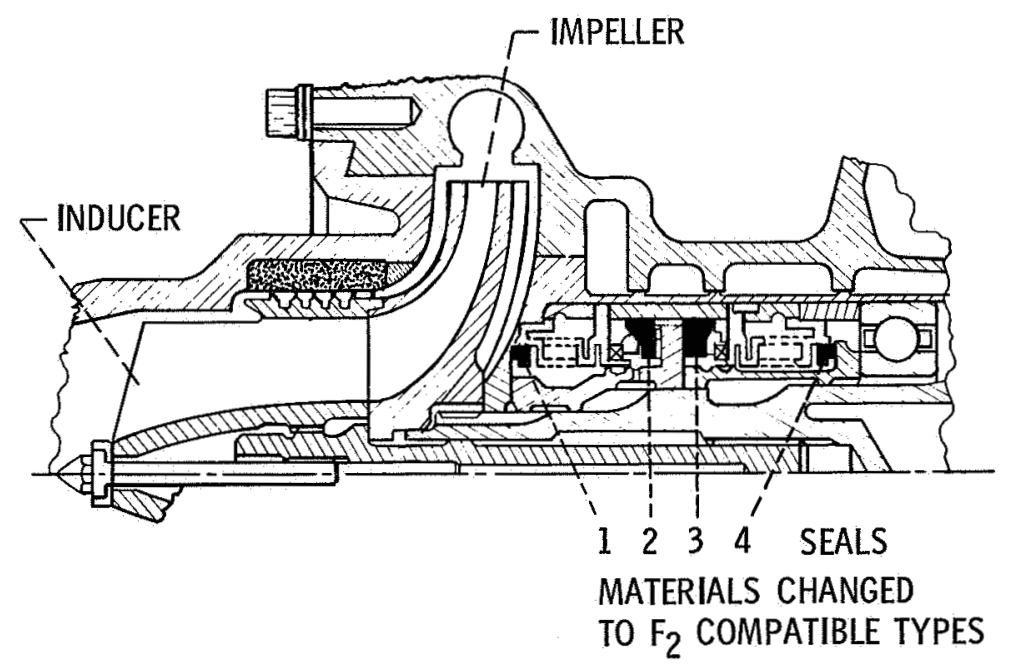

Figure 20. - Fluorine modifications to the RL10A-3-3 oxidizer pump. 
in

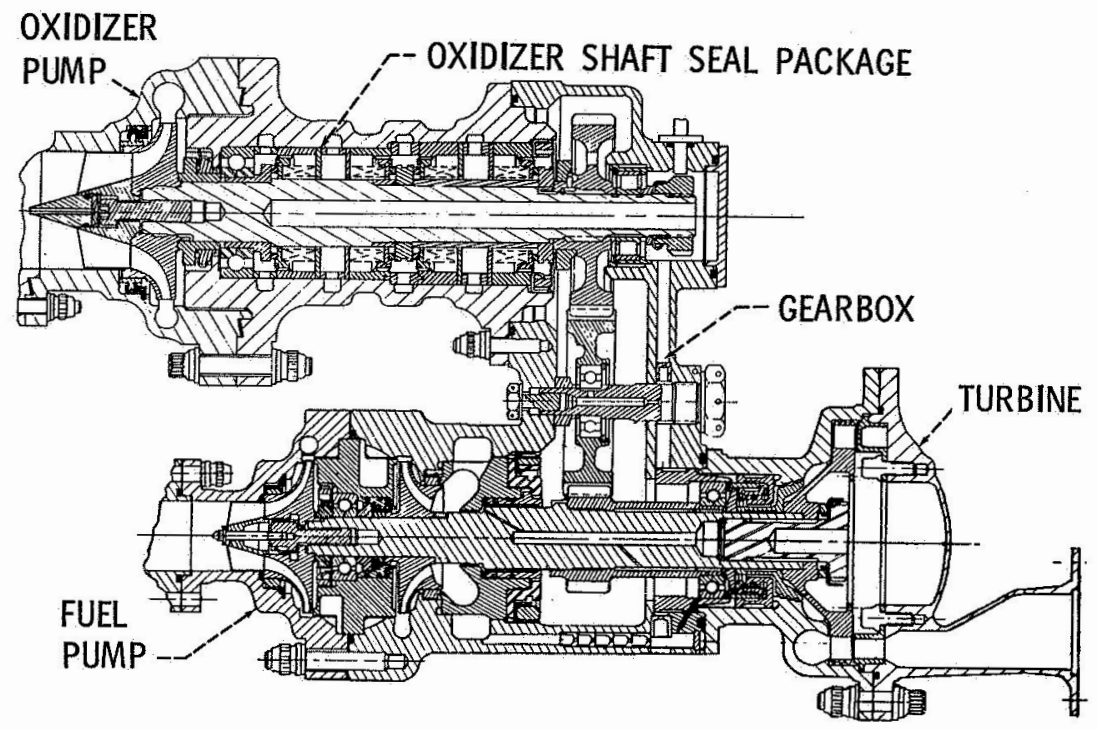

Figure 21. - FLOXImethane turbopump package.
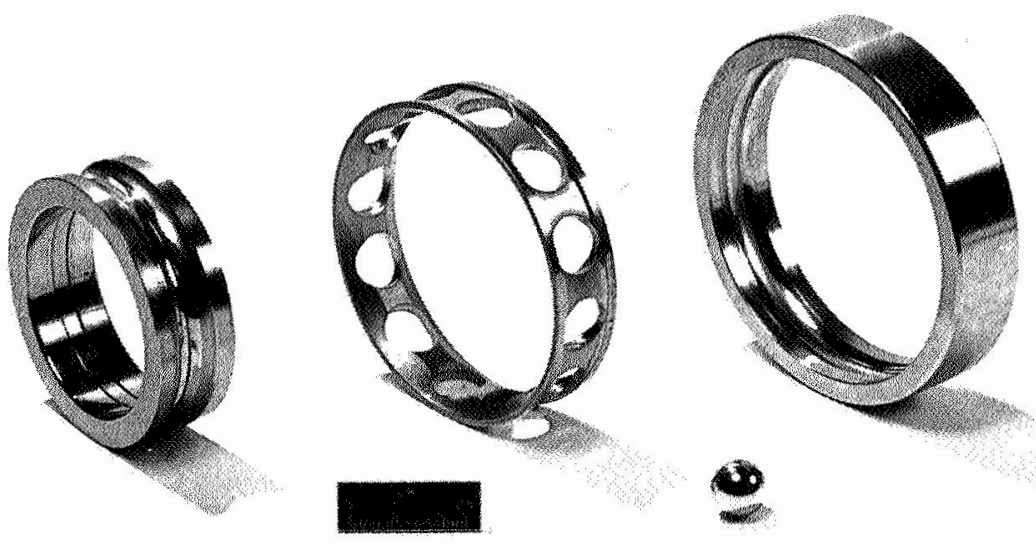

C- $-68-4074$

Figure 22. - Liquid fluorine lubricated bearing. 

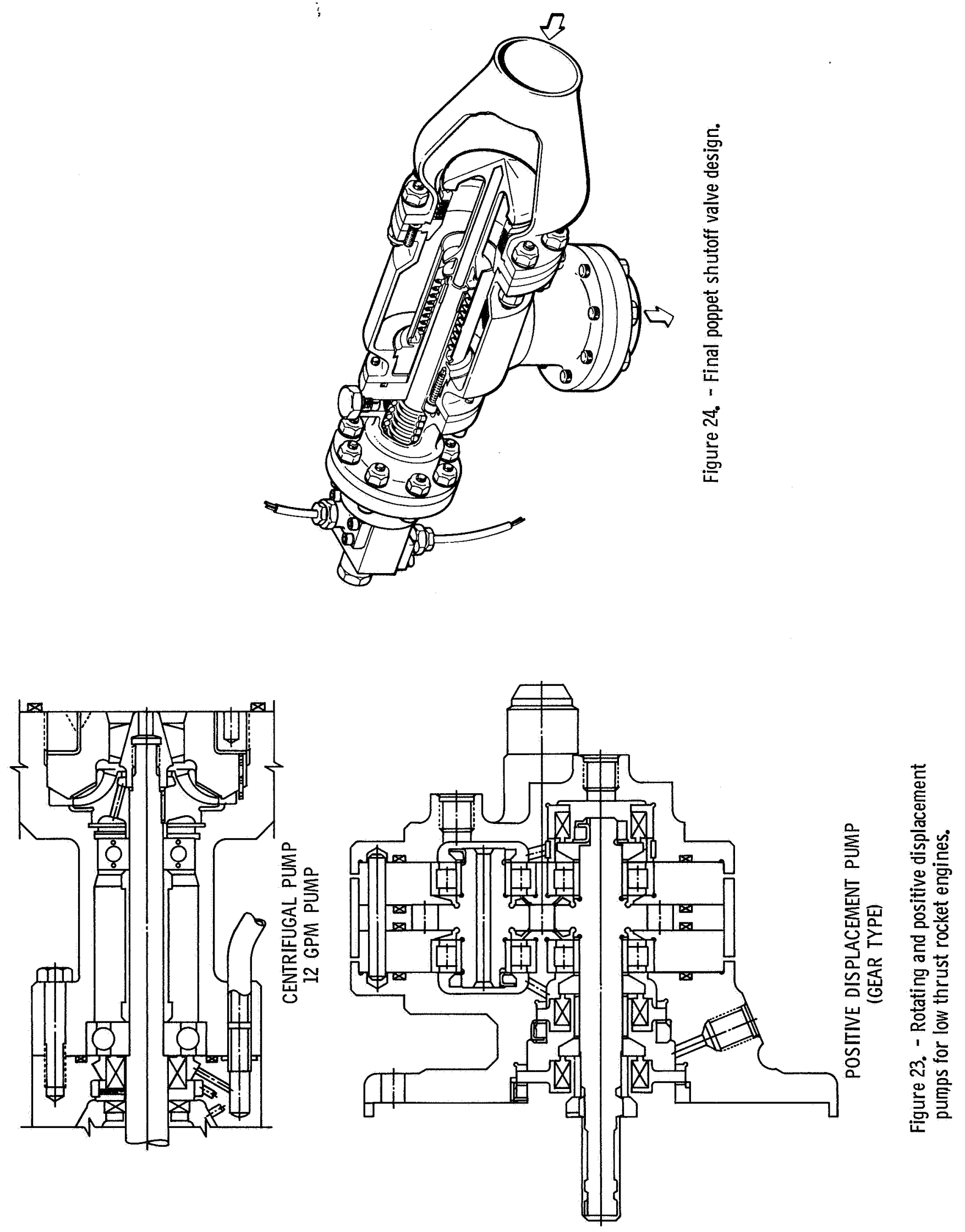


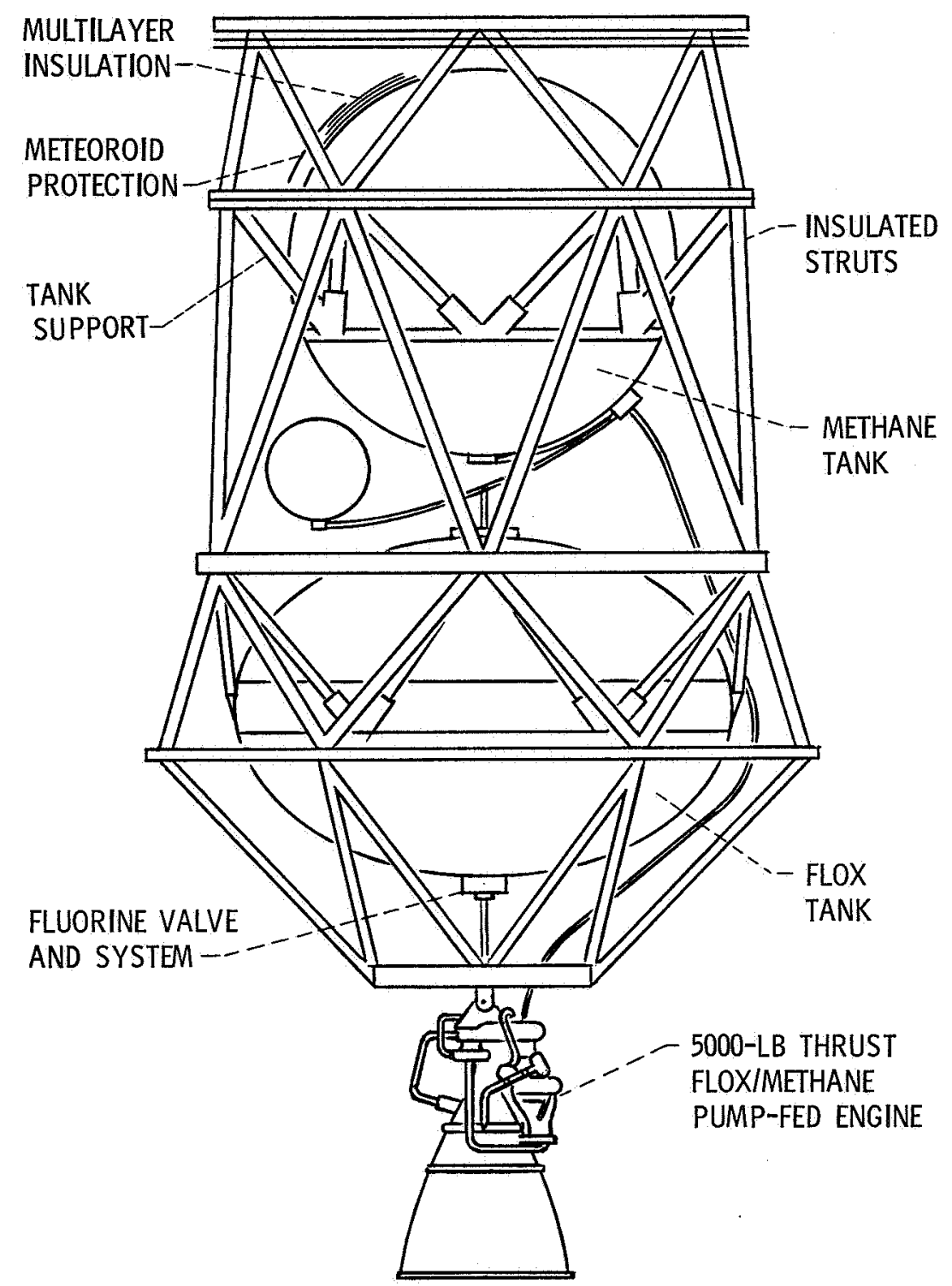

Figure 25. - FLOX/methane research propulsion module. 